\title{
WestVirginiaUniversity
}

THE RESEARCH REPOSITORY @ WVU

Graduate Theses, Dissertations, and Problem Reports

2000

\section{Perception and analysis of Spanish accents in English speech}

Corinne Ann Kropf

West Virginia University

Follow this and additional works at: https://researchrepository.wvu.edu/etd

\section{Recommended Citation}

Kropf, Corinne Ann, "Perception and analysis of Spanish accents in English speech" (2000). Graduate Theses, Dissertations, and Problem Reports. 832.

https://researchrepository.wvu.edu/etd/832

This Thesis is protected by copyright and/or related rights. It has been brought to you by the The Research Repository @ WVU with permission from the rights-holder(s). You are free to use this Thesis in any way that is permitted by the copyright and related rights legislation that applies to your use. For other uses you must obtain permission from the rights-holder(s) directly, unless additional rights are indicated by a Creative Commons license in the record and/ or on the work itself. This Thesis has been accepted for inclusion in WVU Graduate Theses, Dissertations, and Problem Reports collection by an authorized administrator of The Research Repository @ WVU. For more information, please contact researchrepository@mail.wvu.edu. 
Perception and Analysis of Spanish Accents in English Speech

Corinne Ann Kropf

\author{
Thesis submitted to the \\ Eberly College of Arts and Sciences \\ at West Virginia University \\ in partial fulfillment of the requirements \\ for the degree of \\ Master of Arts \\ in \\ Linguistics
}

Johan Seynnaeve, Ph.D., Chair

Susan Braidi, Ph.D.

Norman Lass, Ph.D.

Department of Foreign Languages

Morgantown, West Virginia

2000

Keywords: Foreign Accent, Speech Perception, Speech Analysis, English

Copyright 2000 Corinne Ann Kropf 


\section{Abstract \\ Perception and Analysis of Spanish Accents in English Speech Corinne Ann Kropf}

The purpose of the present study was to determine what relates most closely to the degree of perceived foreign accent in the English speech of native Spanish speakers: intonation, vowel length, stress, voice onset time (VOT), or segmental accuracy. Nineteen native English speaking listeners rated speech samples from 7 native English speakers and 15 native Spanish speakers for comprehensibility and degree of foreign accent. The speech samples were analyzed spectrographically and auditorally to obtain numerical values for each variable. These values and the average foreign accent scores were submitted to Pearson correlations. Results show that the average foreign accent scores were significantly correlated with three variables: the length of stressed vowels $(\mathrm{r}=$ $-.48, \mathrm{p}<.05), \operatorname{VOT}(\mathrm{r}=-.62, \mathrm{p}<.01)$, and segmental accuracy $(\mathrm{r}=.92, \mathrm{p}<.001)$. Segmental accuracy correlated most significantly with the foreign accent scores. 


\section{Acknowledgments}

I would like to thank the several people that made this thesis a reality. Starting from the very beginning, thanks to my whole family for creating me and sustaining me up to the present day. Without all of you, I would not be where I am today. I offer a special thanks to my dad for passing on his determination and "stick-to-it-iveness" to me, to my mom for picking up the phone every time she hears it is me on the other end, to my sister Jennifer for her eternal support, and to my sister Katy for reminding me how exciting life can be if we approach it with a good attitude. I owe endless thanks to my husband Keith for being my linguistic guinea pig at all hours of the day and night, for keeping me well fed during this endeavor, for reading every word of this thesis more carefully than anyone, and for always being there for me with open arms.

My sincere thanks also go out to Joshua Mitchell, Erin Matzen, Darren Dyke, and Juan Carlos Agudelo for being indispensable parts of both my personal and linguistic development at various times. Without all of them continually urging me to stop and smell the linguistic roses along the paths of communication, I might have hurried by, entirely overlooking what is now my reality.

I offer many thanks to the several people at West Virginia University who have aided in the preparation of this thesis. Specifically, I extend my thanks to Dr. Frank Medley for being an unbelievably supportive department chair, to Dr. Susan Braidi for inadvertently talking me into almost everything I have done in linguistics by telling me how challenging it would all be, and to Dr. Johan Seynnaeve for opening up my eyes to all things phonological. I especially wish to thank Dr. Norman Lass for sparking my interest in speech science and for being willing to spend so much time on a student project outside his own department. Without his dedication this project would have been utterly impossible. Thanks also to all the indispensable "speakers," "listeners" and raters who 
graciously volunteered to help me in this project. 
Table of Contents

List of Tables

Page

Abstract

vi

Abstract

vii

Chapter 1 - Literature Review

Intonation

Stress

Vowel Length

Voice Onset Time

10

Segmental Accuracy

14

Chapter 2 - Statement of the Problem

17

Chapter 3 - Methods

Overview

Reading Material 18

Native English Speakers 20

Native Spanish Speakers 20

Recording and Editing 21

Listeners and Listening Sessions

Spectrographic Analysis

Intonation 25

Stress 25

Vowel Length 26

Voice Onset Time 27

Segmental Accuracy 
Foreign Accent and Comprehensibility Scores

Reliability

Analysis Procedures

Intonation

Stress

Vowel Length

Voice Onset Time

Segmental Accuracy

Chapter 5 - Summary

Limitations 40

Conclusions

Suggestions for Further Research

Appendix A: Speakers $\quad 45$

Appendix B: The Paper Doll 46

$\begin{array}{ll}\text { Appendix C: Listening Sessions } & 50\end{array}$ 


\section{List of Tables}

Table

Page

1. Voice Onset Time Measurements after /p/, /t/, and /k/ from Three Studies 12

2. Reading Material Selected for Analysis 19

3. Foreign Accent and Comprehensibility Scores 30

4. Shifts of Five Variables 33

5. Segmental Accuracy 39 


\section{Chapter 1}

\section{Literature Review}

Only one study simultaneously considered the relationships of several speechrelated variables to perceived foreign accentedness without confounding accentedness with comprehensibility ${ }^{1}$. Magen (1998) investigated the effects of errors in syllable structure (epenthetic schwa), vowel quality (tense/lax distinction, reduction), consonants $\left(/ \mathrm{t} \int-\int /\right.$ distinction, final /s/ deletion), voicing (/s-z/ distinction, stop voicing), and stress (lexical and phrasal) on the perception of Spanish-accented English. Two native Spanish speakers were recorded reading English phrases designed to contain opportunities for the variables to be tested. The recordings were edited several times to make them more native like, one variable at a time. The various edited and original phrases were played to monolingual native English speaking listeners who judged the degree of accentedness for each phrase. Results show that "Listeners were sensitive to syllable structure factors, final /s/ deletion, consonant manner [/t $\left[-\int /\right]$, and lexical and phrasal stress" (Magen, 1998, p. 381). It should be noted, however, that only two speakers were used in Magen's (1998) study, and that only one speaker was judged on lexical and phrasal stress (due to technical problems). Magen also suggests that the editing process for certain variables could have been more or less effective than the editing process for other variables. Furthermore, the variables in the study do not represent the full range of possible error types; intonation and vowel length are overlooked entirely.

It is important to thoroughly examine both prosodic and segmental variables for two reasons. First, they provide different types of information about how a speaker

\footnotetext{
${ }^{1}$ Munro and Derwing (1995) distinguish between comprehensibility and intelligibility. They measure comprehensibility as a subjective perceptual phenemonon: how comprehensible the speech seems to the listener. Intelligibility, in their study, is measured objectively: how many words are transcribed correctly into standard orthography by the listener. Due to a lack of consistency in the literature, the two terms will be used interchangably to mean comprehensibility in the present work unless otherwise noted. Accentedness refers to the listener's subjective perception of "foreignness."
} 
manipulates frequency, intensity, and time. This idea is best represented by CouperKuhlen (1986) who shows segments to be the frequency and intensity found in a cross section of time, and prosody to be the changes in frequency and intensity over a continuation of time. Lehiste (1996) adds that while “. . segmental features are identifiable by inspection of the segment itself [,] suprasegmental features are established by a comparison of items in a sequence" (p. 227). Kent and Read (1992, as cited in Kent, Dembowski and Lass, 1996) define prosody as the "... fabric of speech, within which segments are the individual stitches" (p. 213). Second, despite their differences, prosody and segments are interrelated. Just as one faulty stitch can alter the quality of the fabric, the substitution of one segment for another can cause changes in the flow of fo and intensity over time (Munro, 1995).

It is also important to use representative speech samples from a number of speakers with a range of foreign accents. Munro (1995) says "... the potential cues to accentedness may vary from talker to talker ... [and] utterance to utterance" (p. 31). He suggests that different speakers may make different errors. Such differences might be manifested in type, severity, and frequency of the errors. Rekart's (1985, as cited by Magen, 1998) findings that the errors contributing to a strong foreign accent in synthesized speech were not the same as those which contribute to a moderate foreign accent provide empirical support for the need for speakers with a wide range of foreign accents.

Before proceeding, it is necessary to clearly define and explore each variable to be investigated. While only one study (Magen, 1998) has looked at the relative importance of several speech-related variables to the perception of foreign accent in (quasi-)natural speech, there is a considerable amount of research on the perceptual effects of a few or of 
individual variables.

$\underline{\text { Intonation }}$

Intonation has been defined as “. . . the pattern of pitch changes" (Ladefoged, 1975 p. 93; Chreist, 1964) or, more impressionistically, as the melody of speech (Avery and Ehrlich, 1992; Couper-Kuhlen, 1986). Both these definitions refer to the perception of pitch over time. Nooteboom (1997) notes that “... pitch is the perceptual correlate of fundamental frequency" which is the number of cycles per second $(\mathrm{Hz})$ of the lowest harmonic produced by the vibrations of the vocal folds (p. 642). Therefore, intonation can be defined and measured as the pattern of changes in fo over time ('tHart 1984).

Given the above definition, intonation patterns could extend over an infinite amount of time. However, in actual speech, such patterns are restricted to rather short units. There is no general consensus on the nature of these limiting units, but several theories have been proposed. Ladefoged (1975) proposes the tone group as a limiting unit. He says, rather circularly, that "... intonation patterns . . continue till the end of the tone group" (p. 96). Alternatively, Lieberman (as cited in Couper-Kuhlen, 1986) argues that intonation is limited to the length of a breath group. Another limiting unit, a sense group in which all the words are semantically related, was proposed by Klinghardt (as cited in Couper-Kuhlen, 1986). Halliday (as cited in Couper-Kuhlen, 1986) proposes that the clause, a subject and predicate, is the limiting factor on intonational patterns.

Although there may not be agreement on what limits the length of intonation patterns, general intonation patterns can still be observed. Sentence final intonation in English declarations, commands, and wh- questions offers a clear example (Avery and Ehrlich, 1992). Native speakers of English use a pattern of rising, then falling intonation in these sentences: “. . . the pitch rises at the major sentence stress and falls over the 
remaining part of the sentence" (Avery and Ehrlich, 1992, p. 77). By the end of the sentence, the pitch falls to the bottom of the speaker's vocal range. If the pitch does not fall this far, the listener interprets the pattern as non-final and expects the sentence to continue (Avery and Ehrlich, 1992).

It must be taken into account that the perceived pitch and fo are not always equivalent (Couper-Kuhlen, 1986; Lehiste, 1996; Van Els and De Bot, 1987). Avery and Ehrlich (1992) use the word pitch when describing intonation patterns. This use is accurate because it is the listener's perception of fo, not fo itself, that helps the listener to identify the pattern. Lehiste (1996) indicates that listeners attend to the ratios between fundamental frequencies. Therefore, the amount of difference between $200 \mathrm{~Hz}$ and 100 $\mathrm{Hz}$ would be perceived as the same as the difference between $300 \mathrm{~Hz}$ and $150 \mathrm{~Hz}$, both a 2:1 ratio (Lehiste, 1996). In this example, a larger change in absolute frequency must be made in the second case to achieve the same perceptual effect as in the first case. In other words, pitch perception is a function of the ratio of two frequencies, not of the absolute frequencies themselves. This relative perception is what allows listeners to perceive similar intonation patterns in the speech of women, children, and men, who use different absolute speaking fundamental frequencies. It also accounts for the fact that the perceptual effect of any given change in absolute frequency will vary with context (Couper-Kuhlen, 1986; Van Els and De Bot, 1987).

The use of non-native intonation patterns has been shown to affect the perception of foreign accent by native speakers of a language. Van Els and De Bot (1987) report a study where they tested ten experienced Dutch listeners' ability to determine the native language of eighteen speakers reading a story in Dutch. They used nine native Dutch speakers, three native English speakers, three native French speakers, and three 
native Turkish speakers. After recording the speech samples, they removed all intonational information by setting the fo to a constant $175 \mathrm{~Hz}$. They presented the listeners with an unaltered version and the monotonized version. Listening to the unaltered version, the listeners were able to identify the native Dutch speakers with about $94 \%$ accuracy and the non-native speakers with $68 \%$ accuracy. Listening to the monotonized version, the degree of accuracy fell to $88 \%$ for the native Dutch speakers and $43 \%$ for the non-native speakers. These results show that intonation patterns significantly affect a listener's ability to distinguish the speech of native and non-native speakers of Dutch.

Munro and Derwing (1995) also demonstrated the importance of intonation in accent perception. They played speech samples of ten native Mandarin speakers and two native English speakers speaking in English to eighteen native English speaking listeners. The listeners rated the samples for degree of foreign accent. For sixteen of the eighteen listeners (89\%), the degree of foreign accent score they assigned to each speaker correlates with the intonation scores assigned to each speaker by Munro and Derwing. Of the three speech-related variables studied, intonation was shown to have the strongest effect on listener's accentedness judgments.

Intonation also has been shown to affect the perception of foreign accent in synthetic speech. Rekart (1985, as cited in Magen, 1998) incorporated five characteristic components of Spanish accented English into five synthesized sentences. It was determined that intonation patterns “... made the greatest contribution to moderate foreign accent" (p. 382).

$\underline{\text { Stress }}$

"Stress is the degree of force of an utterance" (Kent et al., 1996, p. 214). While 
the perception of stress has been shown to depend on the degree of effort on the part of the speaker (Lehiste and Peterson, 1959, as cited in Lehiste, 1970), there is no one acoustic correlate of speaker effort that can be used to predict the perception of stress. In fact, Lehiste (1970) asserts that "There is no one-to-one correspondence between stress and any single acoustic parameter" (p. 110). Instead of relying on one parameter to predict the perception of stress, it can best be predicted by a simultaneous increase in fo, duration, and intensity (Adams and Munro, 1978; Borden, Harris, and Raphael, 1994; Kent et al., 1996; Fokes and Bond, 1989).

Each vowel has a unique intrinsic fo, duration, and intensity (Peterson and Lehiste, 1960; Lehiste, 1970). This means that, regardless of stress, some vowels naturally have a higher fo, longer duration and greater intensity than other vowels. For example, Lehiste (1970) says that high vowels naturally have a higher fo than low vowels. Saying that stressed vowels exhibit changes in all three acoustic parameters assumes that unstressed vowels are the standard vocalic form. Yet, in linguistics, the opposite is assumed: full vowels are reduced in unstressed positions to the neutral schwa vowel. Delattre (1969) begins his study of vowel reduction by determining the formants of the stressed versions of the vowels. He then reports the effects of unstressing. He finds that while all English vowels undergo reduction and become schwa-like in unstressed positions, reduction on Spanish vowels is not significant for the two high vowels and is minimal for the other three. The most noticeably reduced vowel is /a/ which is slightly raised and backed (Delattre, 1969).

Adams and Munro (1978) investigated native and nonnative speaker use of sentence stress in Australian English. Eight native Australian English speakers and eight native speakers of unspecified Asian languages read a variety of material. The nonnative 
speakers were all “. . graduate teachers of English”; however, no specific proficiency level was given. Other Australian English native speakers were asked to listen to the speech samples and determine where each speaker had placed major sentence stresses.

The results of the listeners' determinations show that the nonnative speakers stressed several syllables that the native speakers did not. All the syllables that were stressed by the native speakers were also stressed by the nonnatives. Further analysis showed that both the native and nonnative speakers made similar changes in fo, duration, and intensity on stressed vowels. Therefore, Adams and Munro conclude that "The real difference between the stress production of the two groups lay not in the mechanisms they used to signal the feature, but rather in their distribution of it" (p. 153).

Fokes and Bond (1989) report similar findings. They had five nonnative speakers of English (one speaker each of Farsi, Japanese, Spanish, Hausa, and Chinese) read two, three, and four syllable English words. In the three and four syllable words it was found that all three components of stress could be observed on the "unstressed" vowels, suggesting that the error was, again, one of stress placement (Fokes and Bond, 1989).

It must not be forgotten, however, that the "stressed" version of a vowel is often considered the normal production of that vowel, and that it must be reduced in unstressed positions. Therefore, indiscriminate stress placement, as reported by Adams and Munro (1978) and Fokes and Bond (1989), could also be interpreted as insufficient vowel reduction. In fact, after analyzing the formant frequencies of the native and nonnative vowel productions, Fokes and Bond state that "The major difference in vowel quality between native and nonnative productions lay primarily in reduced vowels" (p. 359).

In the same study (Fokes and Bond, 1989), subsequent observations revealed that the nonnative speakers' productions of stressed vowels were not native-like either, at 
least in terms of duration. The nonnative speakers "... tended to produce stressed vowels that were too short and unstressed vowels that were too long" (p. 370). The native English speakers' longest stressed vowel was $89.53 \mathrm{~ms}$, and the shortest unstressed vowel was $22.78 \mathrm{~ms}$. The Spanish speaker's productions fell in between the native targets: the longest stressed vowel was $61.24 \mathrm{~ms}$, and the shortest unstressed vowel was $40.82 \mathrm{~ms}$. Fokes and Bond conclude that native English speakers “. . clearly use the length of the vowel to signify syllable stress," their stressed vowels being over 3.5 times the length of their unstressed vowels (p. 369).

Magen (1998) reports that nonnative stress can contribute to the perception of foreign accent. English phrases spoken by one native Spanish speaker were edited to alter the original stress pattern used by the speaker. Lexical and phrasal stress patterns were nativized by altering the fo of the necessary vowels. Both edited and original versions of the phrases were presented to native English speaking listeners who rated the phrases for degree of foreign accent. The nativized version received lower accentedness ratings from the listeners than did the unaltered version. Nevertheless, it should be noted that in the editing process, only one of the parameters of stress was altered. While fo is arguably the most important cue to the perception of stress (Lehiste, 1970, Magen, 1998), duration and intensity also have been shown to be perceptually salient (Adams and Munro, 1978). Vowel Length

The length of vowels before voiced and voiceless consonants has been of interest in the literature since at least 1953 when House and Fairbanks (as cited in Peterson and Lehiste, 1960) found that consonants influence the vowels which precede them. Five years later, Zimmerman and Sapon (1958, as cited in Peterson and Lehiste, 1960) showed that vowel lengthening before voiced consonants was a language specific (English) 
phenomenon as opposed to a physiological one.

In 1960, Peterson and Lehiste undertook a project to determine the length of English syllable nuclei. One important outcome of the Peterson and Lehiste (1960) study is a list of intrinsic lengths for English vowels. After measuring vowel lengths in 1,263 consonant-vowel-consonant (CVC) words spoken by one speaker, they found that the schwa, the reduced vowel, is actually the third shortest vowel, both / $\mathrm{u} /$ and $/ \mathrm{I} /$ being intrinsically shorter. The vowel /ae/ and the diphthongs are the longest vocalic phonemes (Peterson and Lehiste, 1960).

Using the average length of vowels preceding voiceless and voiced consonants, Peterson and Lehiste (1960) report that vowels followed by voiced consonants are 1.5 times the length of those followed by voiceless consonants. More specifically, they found that vowels preceding voiceless plosives are $184 \mathrm{~ms}$, vowels preceding voiceless fricatives are $228 \mathrm{~ms}$, vowels preceding voiced plosives are $280 \mathrm{~ms}$, and vowels preceding voiced fricatives are $376 \mathrm{~ms}$. These findings are based on nine sets of words each containing four minimal contrasts, such as the set rice-rise-ride-right (Peterson and Lehiste, 1960, p. 700).

In a subsequent study of five native English speakers designed to test their findings, Peterson and Lehiste (1960) report that vowels preceding voiced consonants in CVC words were $98 \mathrm{~ms}$ longer than ones preceding voiceless consonants, again a 50\% increase. Flege (1993) reports similar results. He finds that in the speech of ten native speakers of English, the average length of the vowels /i/, /I/, /ae/, /a/, / / /, /e/, and /u/ in a /b_d/ frame were $137 \mathrm{~ms}$ longer than the same vowels in a /b_t/ frame, about a 60\% increase.

In the same study, Flege (1993) measured the lengths of vowels in the /b_d/ and 
/b_t/ frames produced by various nonnative English speakers. Their native languages were Mandarin, Taiwanese, Cantonese, Fukienese, and Hunanese; however, the Cantonese, Fukienese, and Hunanese speakers all learned Taiwanese as children and were considered as part of the Taiwanese group. Of the four subgroups of nonnative speakers (inexperienced Mandarin late learners, inexperienced Taiwanese late learners, experienced Taiwanese late learners, and childhood second language learners) the childhood second language (L2) learners came the closest to approximating the vowel lengths observed in the native speaker control group. The native speakers' vowels before /d/ were an average of $137 \mathrm{~ms}$ (or about 69\%) longer than those before/t/, while the childhood L2 learners' vowels before /d/ were an average of $104 \mathrm{~ms}$ (or about 53\%) longer than those before /t/. The other three experimental groups' vowels before /d/ were an average of only $47 \mathrm{~ms}$ (or about 24\%) longer than those before $/ \mathrm{t} /$.

Flege (1993) asserts that a lack of sufficient lengthening of vowels before voiced consonants affects native speakers' perception of foreign accentedness. In 1988 (as cited in Flege, 1993) Flege obtained foreign accentedness ratings for the speakers used in the 1993 study. He reports that correlations between foreign accent scores and vowel length before /d/ were higher than those between foreign accent scores and vowel length before $/ t /$. This means that the vowels produced in the $/ \mathrm{b} \_t /$ frame were perceived as more "native like" than those in the /b_d/ frame, which were not appropriately lengthened. $\underline{\text { Voice Onset Time }}$

The phonological term "aspiration" refers to the puff of air after syllable-initial voiceless stops in stressed syllables in English. It can be defined more precisely if looked at from a phonetic, rather than a phonological, point of view. What aspiration does is delay the onset of voicing in the following vowel. Therefore, phoneticians measure 
aspiration as the voice onset time (VOT) after voiceless stops. More concretely, Major (1987) and Riney and Takagi (1999) measure VOT as the amount of time from the “... beginning of the release burst [of the voiceless stop] to the onset of periodicity of the succeeding vowel" (Major, 1987, p. 198). Likewise, Flege (1991; Flege, Frieda, Walley, Randazza, 1998, p. 165) defined and measured VOT as “. . . the interval from the onset of the release burst ... to the first positive peak in the periodic portion (vowel) of the signal following the release burst."

Results vary as to how long native English speakers' VOT values are. Two studies (Peterson and Lehiste, 1960; Riney and Takagi, 1999) found VOT to be longer after $/ \mathrm{k} /$ than after $/ \mathrm{p} /$ or $/ \mathrm{t} /$. A third study (Major, 1987), however, found VOT to be longest after /p/. The VOT measurements of native English speakers from the three studies are summarized in Table 1.

The differences in the VOT values found by Major (1987) may be due to the words from which the measurements were derived. Flege (1991; Flege et al., 1998) found that, after/t/, VOT is a function of the height of the following vowel. VOT after/t/ measurements were made of the speech of native speakers of English and native speakers of Spanish speaking English. For both groups of speakers, VOT was longer when the following vowel was a high vowel. They conclude that the variation of VOT with following vowel height is a physiological phenomenon rather than a language-specific one. Because of this conclusion, it is necessary to control for the height of the following vowel when attempting to determine after which consonant VOT is longest.

Major (1987) measured VOT after the word-initial consonants in these words: Pete, tell, cap, and cab. The vowel /i/ after /p/ is the only high vowel in the word list. If Flege's (1991; Flege et al., 1998) findings for /t/ also apply to /p/, then it is possible that 
Table 1

Voice Onset Time Measurements after $/ \mathrm{p} /, / \mathrm{t} /$, and $/ \mathrm{k} /$ from Three Studies

Measurements in ms

Study

$/ \mathrm{p} / \quad / \mathrm{t} / \quad / \mathrm{k} /$

Peterson and Lehiste (1960)

58

69

75

Riney and Takagi (1999)

74.2

74.2

85.2

Major (1987)

82.3

78.3

79.2

the high vowel /i/ causes the VOT after/p/ to be longer in Major's study than it would have been if followed by a mid or low vowel.

Past research offers two findings about VOT which are relevant to the present study (Major 1987; Flege, 1991; Riney and Takagi, 1999). First, some ESL learners can learn to use native-like VOT values. Second, nonnative-like VOT values are correlated with the perception of foreign accent. These two findings are detailed below.

Major (1987) measured the VOT values produced by 60 speakers in the words Pete, tell, cap, and cab. The speakers were seven native English speakers and 53 Brazilian Portuguese speakers learning English. He found that, on average, the VOT values used by the Portuguese speakers were much shorter than those used by the native English speakers, ranging from $29.7 \mathrm{~ms}$ to $63.5 \mathrm{~ms}$ instead of the native $78.3 \mathrm{~ms}$ to $82.3 \mathrm{~ms}$ range. While the general trend was for the nonnative speakers to use shorter than native VOT values, Major notes that some speakers did fall within the native range: “. . . it is indeed possible for some speakers with short-lag VOT values in their [native languages] to become proficient at producing long-lag VOT values" (p. 201). 
In another part of Major's (1987) study, he investigated the relationship between VOT values and the perception of foreign accent. Native speakers of English listened to the 60 speakers and assigned foreign accentedness scores on a scale of 1-256. He determined that nonnative-like VOT values were correlated with the degree of foreign accent perceived and that this correlation was highly significant.

Flege included two groups of Spanish-English bilinguals in his 1991 study of VOT after /t/. One group of bilinguals consisted of ten Spanish speakers who began learning English between ages five and six. The other group consisted of ten Spanish speakers who began learning English as adults. Both groups read eight Spanish and eight English words beginning with /t/. The effects of vowel height on VOT were controlled by choosing four words in each language containing /i/ and four containing / $/$ /.

It was found (Flege, 1991) that average VOT values were much shorter for Spanish words than for English words. Furthermore, it was found that the late English learners did not, as a group, lengthen their English VOT values enough to fall within the native speaker range. The early English learners, on the other hand, produced English VOT with “. . . the same mean values ... as the English monolinguals" (p. 398). This confirms Major's (1987) finding that some English as a second language (ESL) speakers do learn to produce native-like VOT values in English.

In a third study, nonnative-like VOT values were found to correlate with foreign accent perception in the speech of Japanese ESL speakers (Riney and Takagi, 1999). Eleven Japanese ESL speakers read the words part, time, tub, cab, can, and come. The VOT values after word-initial stops were measured and then compared to the VOT values of native English speakers reading the same words. The Japanese ESL speakers' VOT values ranged from $40 \mathrm{~ms}$ to $67.6 \mathrm{~ms}$, and the native English speakers' VOT values ranged 
from $74.2 \mathrm{~ms}$ to $85.2 \mathrm{~ms}$. Again, the nonnative speakers were found to have shorter VOT values than the native speakers. Other native English speakers listened to the Japanese ESL speakers' speech and rated their degree of foreign accent. Consistent with Major's (1987) results, Riney and Takagi found that foreign accent and VOT were positively correlated.

\section{$\underline{\text { Segmental Accuracy }}$}

Segments, or phonemes, are possibly the most salient aspect of speech. While the intuitive definition of a segment as a discrete speech sound is fairly straightforward, an operational definition is more difficult to delineate. Catford (1977) offers a fairly workable definition: a segment is a “. . . stretch of speech ... bounded by moments of rapid change in the state of at least one of the components" (p. 228). The components are voicing, place, and manner of articulation.

With Catford's (1977) definition of a segment, measuring the length of individual segments should not pose much of a problem. Peterson and Lehiste (1960), however, conclude that "In some instances ... the transitions between consonants and vowels involve an overlapping of cues, and in such instances it does not appear meaningful to attempt to determine exact time boundaries" (p. 694).

Brennan, Ryan, and Dawson (1975, as cited in Flege, 1981) found that the frequency of segmental substitutions was highly correlated with the perception of foreign accent. The idea that segmental errors affect native speaker perceptions is further supported by other research. Magen (1998) found that for 20 monolingual English speaking listeners, three segmental deviations significantly affected their perception of foreign accent in the speech of two native Spanish speakers while one other segmental deviation did not. Consonant cluster simplification achieved by inserting schwa in word 
initial position and in -ed endings, the contrast in manner between $/ \mathrm{t} / /$ and $/ \mathrm{J} /$, and the deletion of final /s/ all affected the accentedness scores assigned to the utterances containing these variables. The contrast in voicing between $/ \mathrm{s} /$ and $/ \mathrm{z} /$ was not found to have significant effects on the accentedness ratings.

In another study (Derwing and Munro, 1997), the effects of segmental deletion, insertion and substitution on perceived accentedness were investigated. Twenty-six native English speakers listened to recordings of 48 nonnative speakers, 12 speakers each of Cantonese, Japanese, Polish, and Spanish. Results show that foreign accent scores and segmental accuracy were significantly correlated for only four of the 26 listeners. On an open-ended questionnaire, however, 12 of 13 respondents reported that segmental accuracy was an important factor in their ratings of accentedness. Perhaps this discrepancy is due to the fact that the researchers did not also include segmental distortions in their determination of segmental accuracy.

Flege (1984) says that distortions will not be considered substitutions if consonants are perceived categorically, but distortions can still affect the perception of accent. He proposes that even “... subcategorical phonetic differences ... [may] contribute to the detection of accent" (p. 704). Because Derwing and Munro's (1997) study did not account for segmental distortion, they may have missed an important perceptual variable.

Another study by Munro and Derwing (1995) shows that both phonemic and phonetic errors affect the perception of foreign accent. Phonemic errors were defined as “... either the deletion or insertion of a segment, or the substitution of a segment that was clearly interpretable as an English phoneme different from the correct one" (p. 80). Phonetic errors were defined as “. . . the production of a segment in such a way that the 
intended category could be recognized but the segment sounded noticeably nonnative" ( $\mathrm{p}$. 80). In the study, recordings of ten Mandarin speakers were played to 18 native English speaking listeners who rated each speaker's accent. Although the factor which most significantly correlated with listeners' accent ratings was intonation, phonemic errors were significantly correlated with $78 \%$ of the listener's ratings, and phonetic errors were significantly correlated with $72 \%$ of the listener's ratings. 


\section{Chapter 2}

\section{Statement of the Problem}

Previous research has included the study of the relative effects of prosodic and segmental variations on intelligibility (Anderson-Hsieh, Johnson and Koehler, 1992; Anderson-Hsieh and Koehler, 1988; Munro and Derwing, 1995, Derwing and Munro, 1997). Other studies have investigated the relationship between one variable and the degree of, or ability to detect, foreign accentedness (Flege, 1984; Van Els and De Bot, 1987; Flege, 1993; Munro, 1995; Riney and Flege, 1998; Riney and Takagi, 1999). There is, however, no body of literature which attempts to determine the relative effects of several variables, both prosodic and segmental, on the perception of foreign accentedness. Flege (1987) concludes that ". . . the aim of most instrumental studies has not been to establish which dimension(s) contribute(s) most importantly to foreign accent" (p. 288).

The aim of the present study is to determine the relationship of various prosodic and segmental aspects of speech to American English native speakers' perceptual ratings of foreign accentedness in the English of native Spanish speakers. The prosodic variables to be considered in this study are declarative sentence final intonation; the intensity, duration, and fundamental frequency (fo) of stressed versus unstressed vowels; vowel length before voiced and voiceless consonants; and the voice onset time (VOT) of voiceless stops. Segmental accuracy will also be considered. The amount of error observed for each variable will be individually compared to the listener scores of accentedness, and the relationships will be analyzed for emergent patterns. 


\section{Chapter 3}

Methods

Much research has been conducted that sheds light on speech-related factors that influence the degree of perceived foreign accent. However, to date there has been no comprehensive investigation to determine which of the many speech-related variables influences the perception of a foreign accent most heavily. The aim of the present study is to fill that gap in the literature and to begin to shed some light on precisely what listeners attend to when asked to rate foreign accentedness.

\section{$\underline{\text { Overview }}$}

Twenty-four speakers were recorded reading two paragraphs. Seven were native speakers of English and seventeen were native speakers of Spanish. Two sentences from each paragraph were later selected for use in this study. These sentences were played to 19 native English speaking listeners who rated each speaker for comprehensibility and foreign accentedness. The sentences were then analyzed spectrographically and by ear.

\section{$\underline{\text { Reading Material }}$}

Speakers read two paragraphs: The Rainbow Passage (Fairbanks, 1960) and The Paper Doll (see Appendix A), written by the author for the present study. Each paragraph contains all the phonemes of American English. For this study, however, only two consecutive sentences from each paragraph, reproduced in Table 2, were used. These sentences were selected because, when combined, the four sentences contain all the English consonant phonemes except [3] and all the simple vowels of English and one diphthong, [aj]. The diphthong was treated like the other vowels in the analysis because there was no apparent reason not to. 
Table 2

$\underline{\text { Reading Material Selected for Analysis }}$

\begin{tabular}{|c|c|c|}
\hline Passage & Style & Sentences \\
\hline \multirow[t]{2}{*}{ Rainbow Passage } & Orthography & $\begin{array}{l}\text { People look but no one ever finds it. When a } \\
\text { man looks for something beyond his reach } \\
\text { his friends say he is looking for the pot of } \\
\text { gold at the end of the rainbow. }\end{array}$ \\
\hline & IPA Transcription & 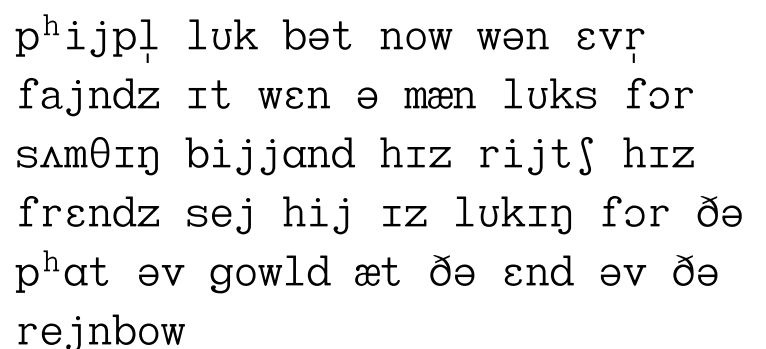 \\
\hline
\end{tabular}

The Paper Doll Orthography She accepted Joe's offer. He took the scissors while she continued to hold the halfcut sheet of paper.
IPA Transcription $\quad \int i j æ k s \varepsilon p t ə d$ dzowz of $r_{1} h i j$ $t^{\text {huk }}$ ðə sizrz wajl $\int i j$ kənt ${ }^{h}$ Injuwd tə howld ðə hæf $k \Lambda t$ sijt əv phejpr

Note. The transcription is broad and based on idealized speech. The aspiration of $\mathrm{p}, \mathrm{t}$, and $\mathrm{k}$ are noted, however, because it is necessary for the analysis of voice onset time. IPA = International Phonetic Alphabet. Adapted from Fairbanks (1960) and The Paper Doll, written by the author for the present study. 


\section{$\underline{\text { Native English Speakers }}$}

Seven native English speakers (see Appendix B) from West Virginia were included in the study for use as a reference for the analysis of the accented speech. Of the seven, four were female and three were male. Two reported speaking Spanish moderately well, and the others either spoke no foreign language or reported poor proficiency in a foreign language. One speaker reported having a (unspecified) speech, language or hearing disorder, but also noted that it had been corrected and did not affect her pronunciation. The language backgrounds of these speakers are similar to those of the listeners (described below). This similarity is expected to ensure that the listeners will recognize the native English speech as native.

\section{$\underline{\text { Native Spanish Speakers }}$}

Fifteen of the seventeen native Spanish speakers (see Appendix B) recorded were used in the study to provide speech samples with varying degrees of foreign accent. The data from two speakers (speakers 19 and 20) were damaged during the editing process and, consequently, were not included in the study. Of the remaining fifteen speakers, eight were female and seven were male. One speaker was from Nicaragua, eight were from Spain, and six were from Colombia. Thirteen reported speaking at least one other language in addition to Spanish and English, usually French.

At the time of the recording, all but two of the native Spanish speakers were completing a Master's program at West Virginia University and teaching Spanish to undergraduates. Of the remaining two, one was a graduate student teaching French to undergraduates and the other was an undergraduate student at the same university. The speakers reported living in the United States for periods of time ranging from three months to five years. Their average length of time in the United States was 22.8 months. 
Seven of the speakers reported that some member of their family also spoke at least some English. Five people reported speaking English in their home in their native country sometimes, and one reported speaking English often in that environment. Seven reported speaking English in their United States home sometimes, and three reported doing so often. Only four of the fifteen speakers reported never speaking English in their homes in their native country or in the United States.

When asked about their English studies, three speakers reported studying only American English, and five reported studying only British English. The remainder reported studying both, but one speaker was not sure which variety she had studied. Their length of formal English instruction varied from one year to fourteen years, the average being 7.7 years. The earliest any speaker had begun studying English was age six, and the latest age for beginning instruction was twenty. Their average age of first instruction of any variety of English was 12.6 years old.

Each speaker was asked to rate her own degree of foreign accent on a scale of one to seven where one means no foreign accent and seven means a heavy foreign accent. This is the same scale that was used later in the study by the native English speaking listeners. Self appointed scores ranged from three to seven, indicating that every speaker judged herself as having some degree of foreign accent. The average self score was five. Interestingly, eleven speakers indicated that they would like to change the way they sound in English if they could, one did not know if she would like to change, and three did not want to make any changes.

$\underline{\text { Recording and Editing }}$

Recordings were made on a Marantz Portable Cassette Recorder PMD222 over three consecutive days and were all administered by the author. Speakers sat about six 
inches from a Shure SM58 microphone and read two paragraphs with a short pause in between. Some speakers were asked to repeat the reading due to technical or speakerrelated problems. Then the speakers were asked to chose a picture to describe, and their descriptions were also recorded. The descriptions are not used in the present study.

After the recordings were made, two consecutive sentences were selected from each paragraph for a total of one item (four sentences) per speaker. The cassette recording was played into a Macintosh computer and edited with ProTools software which sampled the original recording at $44.1 \mathrm{kHz}$. Next, the data was trimmed to contain only the selected items. Each item was then duplicated, making a total of 44 items, two per speaker. Finally, the data was ordered so that no two native English speakers occur without at least one intervening native Spanish speaker and so that the two items of one speaker never occur together. After the editing process was complete, the data was transferred back onto cassette. This new cassette recording was used in the listening session and in the subsequent spectrographic analysis of the items themselves.

\section{$\underline{\text { Listeners and Listening Sessions }}$}

In the literature reviewed above, the number of listeners involved ranged from 5 to 26 and represented a variety of linguistic training, from totally untrained to professional linguist. It was determined that, for the present study, students with little or no training in language and linguistics would be included. These levels of training are assumed to be representative of the general university population where the nonnative speakers recorded earlier interact with native English speakers on a daily basis. Furthermore, the native English speakers recorded earlier also represent little or no language and linguistics training. Thus, the two native English speaker groups, the speakers and the listeners, are similar, and the listeners will be likely to recognize the other native English speakers as 
such.

A description of the linguistic backgrounds of the listeners shows the similarity between the native English speakers and listeners used in the present study. Listeners were 19 native English speakers (8 females and 11 males) who were not already involved in the study. All the listeners were undergraduate and graduate students at West Virginia University. Four identical listening sessions were held, the second and third were on the same day, eight days after the first, and the fourth was thirteen days after the first. Six listeners attended the first session; two attended the second, two the third, and nine the fourth. One listener was a student of Japanese and German and was enrolled in an introductory linguistics course for foreign language majors, and two others were also enrolled in the same introductory linguistics course as well as German. One other listener also had limited experience with German and French. One listener was enrolled in an introductory linguistics course for non-language majors. Three listeners were enrolled in a first semester Spanish course and five were enrolled in a second semester Spanish course at the time of the listening sessions. One other listener had also had some Spanish courses as an undergraduate. Additionally, four listeners were enrolled in a fourth semester French course. The remaining listener was participating in a steel drum construction apprenticeship program.

Each session lasted approximately one hour. Listeners were given written instructions (see Appendix C) describing the two rating tasks. An example of how to use the rating scales was included in the instructions. While the listeners followed along, the instructions were read out loud to them to ensure their full understanding. A period for questions was allowed, but none arose.

First, listeners heard a 19-minute cassette tape containing the 44 items spoken by 
the 22 speakers as described above. The cassette was played through the internal speaker of a Recordex model 2820AV. Listeners rated the items for degree of comprehensibility on a seven point Likert scale where one meant completely comprehensible and seven meant completely incomprehensible. Following a short break, they heard the same cassette again. This time they rated the items for degree of foreign accent on a similar Likert scale where one meant no foreign accent and seven meant a heavy foreign accent. The listeners were unaware that each speaker was presented twice until they were informed at the end of the listening session.

While the goal of this study is to investigate foreign accent and not comprehensibility, it was decided that the need for the listeners to consciously distinguish the two was necessary. This decision is based on the study by Munro and Derwing (1995) that found "that although strength of foreign accent is correlated with perceived comprehensibility and intelligibility, a strong foreign accent does not necessarily reduce the comprehensibility or intelligibility of L2 speech" (p. 74). In order for them not to confound comprehensibility and foreign accent, listeners were asked to first rate comprehensibility, and then foreign accent. They were asked to rate comprehensibility first so that, when rating foreign accent, they would know what factors they had already considered and should not consider again.

Spectrographic analysis

The same speech samples heard by the listeners were analyzed by the author with Praat 3.8 software on a Macintosh computer. The recording of the speakers was played by the Recordex $2820 \mathrm{AV}$ into the computer where it was sampled by Praat 3.8 at a sample rate of $44.1 \mathrm{kHz}$. Information about intonation, stress, vowel length, and voice onset time was observed and recorded. 


\section{Intonation.}

The beginning and end of each phrase were determined visually by looking at the spectrogram portion of the sound editor screen. The time of each phrase beginning and ending was recorded. Then, looking at the pitch portion of the analysis editor screen, information about intonation was obtained by moving the cursor to the previously determined phrase beginnings and endings and recording the given pitch.

Values of fo were recorded at the beginning and end of each of the four sentences included in the reading material. This yielded four phrase initial fo values and four phrase final fo values. Each group of values was averaged to yield one phrase initial fo value and one phrase final fo value. These values were then examined to find the intonation shift. The intonation shift is the amount of change in $\mathrm{Hz}$ between average phrase initial fo and average phrase final fo.

\section{$\underline{\text { Stress. }}$}

The presence of stress on a syllable was determined by listening to the recording of each native English speaker and noting which syllables sounded stressed to the author. Syllables judged to be stressed by every native English speaker without exception were called stressed. Syllables transcribed in Table 2 as [ə] were called unstressed, and all other vowels were excluded from consideration.

Once the stressed syllables had been determined, three of them were chosen as representatives to be used in calculating the average values for stressed vowels: [ow], [ej], and the diphthong [aj]. These vowels were selected for two reasons. First, although the syllables stressed by all the native English speakers did include lax vowels and [a], the wide variety of different inherent durations of the vowels made their average meaningless. The three vowels selected were observed to be of similar length and are therefore 
averageable. Second, stressed lax vowels were excluded from the calculations because native Spanish speakers do not often pronounce lax vowels in English. Therefore, the native Spanish speakers" "lax" vowels would be longer than expected due to segmental error rather than stress.

The three parameters of stress (duration, fo and intensity) were measured for each relevant vowel. Duration was measured by visually and auditorally determining the length of each vowel on the spectrogram and waveform portions of the speech editor screen. Once the desired area of the spectrogram was highlighted by the cursor, its duration could be observed. After recording the duration of each vowel, an approximate center point in time was determined visually. This center point was recorded and then used to locate the vowel on the analysis editor screen by moving the cursor to the recorded time. Once the cursor was positioned on the analysis editor screen, the vowel's fo and intensity could be observed by looking at the pitch and intensity portions of the screen respectively.

As vowels have intrinsic differences in duration, fo and intensity, the changes that stressed vowels undergo will be quantified by averaging the measurements of each of the three parameters of all unstressed vowels and determining the amount of change between those averages and the corresponding average measurements of all stressed vowels. The differences between the parameters of stressed and unstressed vowels will be referred to separately as the duration stress shift, the fo stress shift and the intensity stress shift.

\section{Vowel length.}

The duration of each vowel was obtained according to the method described in the preceding subsection about stress. The durations were obtained once and, therefore, the same measurements will be used in the considerations of vowel length as related to stress 
and to consonant voicing.

Vowels' intrinsic differences again must be accounted for when looking at the change in duration of vowels before voiced and voiceless consonants. One way to do this, used by Peterson and Lehiste (1960), is to average the lengths of all vowels which precede voiceless consonants and subtract that average length from the average length of all vowels preceding voiced consonants. In the present study the averages will be examined to determine the amount of change between them. The resultant calculation will be referred to as the vowel length shift.

Voice Onset Time.

VOT was measured for all relevant syllable-initial voiceless stops. The six chosen stops were all those that occurred either in unstressed syllables (containing schwa) or in syllables that were stressed by every native English speaker. Of the chosen stops, three were in unstressed syllables: "ted" of accepted, "con" of continued, and to. The remaining three occurred in stressed syllables: took, "tin" of continued, and cut.

VOT values were measured by visually determining the length of the selected stops from their release burst to the onset of the following vowel. The area was then highlighted by the cursor and the duration was observed and recorded.

In order to avoid the confounding effects of various phonetic environments on VOT values, all VOT values of syllable-initial voiceless stops in unstressed syllables will be averaged and then compared to the average of all VOT values of syllable-initial voiceless stops in stressed syllables to determine the amount of change.

\section{Segmental accuracy}

The author listened to each speaker, played over the same Recordex machine as used in the listening sessions, to determine the number of incorrectly produced phonemes, 
or segments. The transcription in Table 2 was used to determine the target segments, of which there are 172. A segmental error was defined as a substitution, deletion, insertion or distortion. In order to ensure the reliability of the segmental accuracy scores, they were rated twice under similar conditions, six days apart. After the second rating session, the two scores for each speaker were compared. Any speaker whose two scores were not exactly the same was rated a third time so the author could reconcile the two conflicting scores. This resulted in one segmental accuracy score per speaker.

It was determined that the reliability of the segmental accuracy scores should be tested further because the author knows all the speakers and may have already had opinions about their speech. Two speech pathology students from West Virginia University, who also spoke Spanish, were asked to judge segmental accuracy. Neither of these students knew any of the speakers. After receiving instructions on what constituted an error, they were asked to rate the first two speakers together. They then discussed their opinions and came to consensus on those two speakers. They rated the remaining speakers individually at their leisure. 


\section{Chapter 4}

Results and Discussion

\section{$\underline{\text { Foreign Accent and Comprehensibility Scores }}$}

The listeners heard each speaker twice for each rating task. This resulted in two foreign accent scores and two comprehensibility scores per speaker for each listener. Because the listeners gave similar scores during time one and time two for both rating tasks, the scores were averaged to yield one foreign accent score and one comprehensibility score per speaker per listener. All listeners' scores for each task were added together and divided by the number of listeners to find an average score for each speaker. Therefore, each speaker was assigned one foreign accent score and one comprehensibility score. These scores are shown in Table 3.

The listeners were asked to rate the comprehensibility of the speakers to help them differentiate between the concepts of foreign accent and comprehensibility. To determine their success or failure in distinguishing the two concepts, the foreign accent scores and comprehensibility scores were correlated using a Pearson correlation as described in Hatch and Lazaraton (1991). It was found that the two scores are significantly correlated $(\mathrm{r}=.94, \mathrm{p}<.001)$, which means that the listeners were essentially rating the same thing twice. However, because the comprehensibility scores were generally lower than the foreign accent scores, indicating that even heavily accented speakers were fairly comprehensible, it appears that there was some differentiation between the two concepts.

Munro and Derwing (1995) also found that foreign accent and comprehensibility were correlated, but they noted that a heavy accent does not always imply poor comprehensibility. As the listener judgments in the present study are consistent with 


\section{Table 3}

Foreign Accent and Comprehensibility Scores

\begin{tabular}{|c|c|c|}
\hline Speaker & Foreign Accent Score & Comprehensibility Score \\
\hline 1 & 4.82 & 2.95 \\
\hline 2 & 5.84 & 4.24 \\
\hline 3 & 6.16 & 3.87 \\
\hline 4 & 4.47 & 2.68 \\
\hline 5 & 4.84 & 2.87 \\
\hline 6 & 4.53 & 2.34 \\
\hline 7 & 5.37 & 3.16 \\
\hline 8 & 4.24 & 2.29 \\
\hline 9 & 5.24 & 3.45 \\
\hline 10 & 1.45 & 1.32 \\
\hline 11 & 1.24 & 1.89 \\
\hline 12 & 1.26 & 1.21 \\
\hline 13 & 3.55 & 2.29 \\
\hline 14 & 1.08 & 1.18 \\
\hline 15 & 4.92 & 2.84 \\
\hline 16 & 5.29 & 3.45 \\
\hline 17 & 4.37 & 1.87 \\
\hline 18 & 5.21 & 3.47 \\
\hline 21 & 2.82 & 1.82 \\
\hline 22 & 1.05 & 1.13 \\
\hline 23 & 1.05 & 1.24 \\
\hline 24 & 1.08 & 1.11 \\
\hline
\end{tabular}

Note. The foreign accent scores are based on a seven point Likert scale where one meant no foreign accent and seven meant a heavy foreign accent. Comprehensibility scores are based on a seven point Likert scale where one meant completely comprehensible and seven meant completely incomprehensible. Speakers 10, 11, 12, 14, 22, 23, and 24, in bold, are native English speakers. 
those in Munro and Derwing's study, it will be assumed that the foreign accent ratings are a valid measurement of foreign accent and that they are not confounded with comprehensibility.

\section{$\underline{\text { Reliability }}$}

The reliability of the listeners in judging foreign accent was measured by correlating all possible pairs of listeners using Pearson correlations. The values of $r$ ranged from .81 to .98 , all of which are highly significant $(\mathrm{p}<.001)$.

The reliability of the author to consistently measure vowel length and VOT length on the spectrogram was also investigated. After taking all the necessary measurements from each speaker's spectrogram, the first speaker to be measured, number 14, was measured again. The original measurements were not consulted while the second measurements were being taken. After comparing the first measurements with the second, it was found that all values were within three ms of each other. Therefore, it is assumed that the measurements are reliable.

It was not necessary to check the reliability of the other spectrographic measurements because they were based on the length measurements. For example, after the center point of a vowel was determined, the computer automatically provided information about frequency and intensity.

The reliability of the author and the other two raters to judge segmental accuracy was measured by correlating all possible pairs of raters. The values of $r$ ranged from .89 to .95 , all of which are highly significant $(\mathrm{p}<.001)$.

\section{$\underline{\text { Analysis Procedures }}$}

For all of the variables investigated, the following procedure was employed: 1. the absolute measurements of each speaker's data were examined to determine the 
amount of change in any given variable (variable $\mathrm{X}$ ) from one context to another (referred to as the "X shift");

2. the range of native speaker shifts for variable $\mathrm{X}$ was recorded;

3. a scatter plot graphing the foreign accent score with variable $X$ was drawn to see if the variation was linear or not;

4. for each linear variation (six out of six), a Pearson correlation was performed on the foreign accent score and variable $\mathrm{X}$.

The measurements for each of the variables except segmental accuracy are reported in terms of their shift in order to facilitate comparison among speakers.

Absolute measurements in ms are not discussed because speaking rate was not controlled. Similarly, people have natural differences in fo and intensity which renders these absolute measurements incomparable as well.

Speaker 11, a native English speaker, was not used in the following analysis. As can be seen in Table 3 and Table 4, his scores did not fall within the native speaker range established by the other six native English speakers for comprehensibility, intonation, stress in ms, or VOT. For this reason, and because he was characterized by the author as a mumbler, his data is not used in any calculations, although it is included in the tables where scores are reported.

\section{Intonation}

The intonation shift measures how many times higher the average phrase-initial fo is than the average phrase-final fo. The intonation shifts of each speaker are shown in Table 4.

The range of the native English speakers' intonation shifts was from 2.10 to 4.63 . This means that the average phrase-initial fo was between 2.10 and 4.63 times higher than 
Table 4

$\underline{\text { Shifts of Five Variables }}$

\begin{tabular}{|c|c|c|c|c|c|}
\hline \multirow{2}{*}{$\begin{array}{l}\text { Speaker } \\
\text { Shift }\end{array}$} & \multirow{2}{*}{$\begin{array}{l}\text { Intonation Shift } \\
\text { in } \mathrm{Hz}\end{array}$} & \multirow{2}{*}{$\begin{array}{l}\text { Stress Shift } \\
\text { in } \mathrm{ms}\end{array}$} & \multirow{2}{*}{$\begin{array}{l}\text { Stress Shift } \\
\text { in } \mathrm{Hz}\end{array}$} & \multirow{2}{*}{$\begin{array}{l}\text { Stress Shift } \\
\text { in } \mathrm{dB}\end{array}$} & \multirow{2}{*}{$\begin{array}{l}\text { VOT } \\
\text { in } \mathrm{ms}\end{array}$} \\
\hline & & & & & \\
\hline 1 & 4.40 & 2.56 & 1.06 & 0.97 & 1.62 \\
\hline 2 & 1.60 & 2.06 & 1.07 & 1.03 & 1.19 \\
\hline 3 & 1.06 & 2.72 & 0.85 & 0.96 & 1.65 \\
\hline 4 & 1.46 & 3.60 & 0.88 & 1.00 & 1.70 \\
\hline 5 & 4.84 & 3.59 & 1.00 & 1.03 & 1.18 \\
\hline 6 & 1.11 & 3.39 & 0.90 & 0.95 & 1.44 \\
\hline 7 & 1.94 & 2.59 & 0.98 & 1.04 & 1.29 \\
\hline 8 & 1.60 & 3.35 & 1.22 & 1.08 & 0.87 \\
\hline 9 & 4.52 & 2.49 & 0.97 & 1.07 & 2.16 \\
\hline 10 & 4.63 & 3.56 & 1.04 & 0.99 & 1.70 \\
\hline 11 & 1.42 & 2.34 & 1.00 & 0.89 & 7.24 \\
\hline 12 & 2.88 & 4.24 & 0.93 & 1.06 & 2.86 \\
\hline 13 & 1.32 & 2.70 & 0.94 & 1.07 & 2.07 \\
\hline 14 & 4.01 & 3.51 & 0.93 & 1.05 & 2.24 \\
\hline 15 & 1.28 & 3.21 & 1.00 & 1.06 & 1.49 \\
\hline 16 & 1.87 & 2.47 & 0.99 & 1.00 & 1.06 \\
\hline 17 & 1.47 & 3.16 & 0.99 & 1.04 & 1.48 \\
\hline 18 & 2.62 & 4.96 & 0.75 & 1.04 & 1.59 \\
\hline 21 & 1.45 & 4.67 & 0.91 & 1.06 & 2.82 \\
\hline 22 & 2.62 & 3.31 & 0.93 & 1.02 & 2.50 \\
\hline 23 & 2.10 & 3.53 & 0.75 & 0.99 & 1.98 \\
\hline 24 & 2.51 & 4.13 & 1.00 & 1.07 & 1.71 \\
\hline
\end{tabular}

Note. Native English speakers are in bold. 
the average phrase-final fo. The range of the native Spanish speakers' intonation shifts was from 1.06 to 4.84, overshooting the native English speaker range on both extremes. When the intonation shifts and foreign accent scores were submitted to a Pearson correlation, the results were not significant $(r=-.37, \mathrm{p}>.05)$.

It is difficult to compare the present findings to previous research for methodological reasons. VanEls and DeBot (1987) investigated the effect of intonation on the listeners' ability to differentiate native from nonnative speech. They did not consider the relationship between intonation and degree of foreign accent. Therefore, no direct comparison with the present results can be made.

The results for the present study do not agree with those of Munro and Derwing (1995). Munro and Derwing found that intonation scores were significantly correlated with foreign accentedness ratings for 16 of their 18 listeners. They also note that, of their three speech-related variables, intonation had the strongest effect on the perception of foreign accent. However, in the present study, intonation was not shown to have a significant effect on the perception of foreign accent.

Two methodological differences may help to explain this disagreement. First, in the present study, the average foreign accent score assigned by the 19 listeners was used in the correlations. Conversely, in Munro and Derwing's (1995) study, they correlated each individual listener's accent score with intonation and then tallied the number of significant correlations. Second, phrase initial and phrase final intonation were measured in $\mathrm{Hz}$ and an intonation shift was determined for use in the present study. Munro and Derwing, however, rated intonation impressionistically on a nine point scale and submitted those ratings to the correlation. It is possible that the contradictory findings are due to the different ways of quantifying intonation. 


\section{Stress}

Stress was measured as the three parameters of length, frequency, and intensity. For each parameter, a separate shift was calculated. These shifts are reported in Table 4. The stress shift in ms indicates how many times longer the average duration of vowels in stressed syllables was than that of the vowels in unstressed syllables. The stress shift in $\mathrm{Hz}$ indicates how many times higher the average fo of vowels in stressed syllables was than that of the vowels in unstressed syllables. The stress shift in $\mathrm{dB}$ indicates how many times greater the average intensity of vowels in stressed syllables was than that of the vowels in unstressed syllables.

The native English speakers' range of stress shifts in ms shows that their stressed vowels were 3.24 to 4.24 times the length of their unstressed vowels. The native Spanish speakers' stressed vowels ranged widely from 2.06 to 4.96 times the length of their unstressed vowels. The stress shift in ms was found to be significantly correlated with the perception of foreign accent $(r=-.48, \mathrm{p}<.05)$.

The native English speakers' ranges of the stress shifts in $\mathrm{Hz}$ and $\mathrm{dB}$ were both very small, from .75 to 1.04 and from .99 to 1.07 respectively. These shifts are similar to those of the native Spanish speakers, which were .75 to 1.22 and .95 to 1.08 respectively. This indicates that both groups showed little difference in the frequency and intensity of their stressed and unstressed vowels. The results of the correlations between these elements of stress and the foreign accent scores show that these small changes were not significant in the perception of foreign accent: for the stress shift in $\mathrm{Hz}, \mathrm{r}=.15(\mathrm{p}>.05)$, and for the stress shift in $\mathrm{dB}, \mathrm{r}=-.21(\mathrm{p}>.05)$.

The present findings about the length of stressed syllables are similar to those reported by Fokes and Bond (1989). Fokes and Bond found that native English speakers' 
stressed syllables were more than 3.5 times longer than their unstressed ones. In the present study, it was found that the native English speakers' stressed vowels were between 3.24 and 4.24 times longer than their unstressed ones. Because Fokes and Bond did not investigate the relationship of stress to foreign accent, no comparison with the present study can be made in that respect.

Magen (1998) found that nativizing the fo of stressed syllables improved foreign accent scores for one speaker. In the present study, the fo shift calculated for the relevant syllables did not have a significant effect on the degree of perceived foreign accent. This difference may be due to the fact that Magen used one speaker in her consideration of stress while twenty two speakers were used in the present study.

No comparison with previous research can be made in regards to the $\mathrm{dB}$ stress shift which was found to be non-significant in the present study. Neither Fokes and Bond (1989) nor Magen (1998) considered intensity in their considerations of stress.

\section{$\underline{\text { Vowel Length }}$}

Measurements of vowel length could not be used to find the vowel length shift. This shift was intended to measure how many times longer vowels before voiced consonants were than vowels before voiceless consonants. However, due to the inherent differences in the vowel lengths produced by the native English speakers in both environments, an average of either of these would be meaningless. While it could have been informative to find the vowel length shift of one vowel or of one class of vowels, none occurred enough times in each environment to lend itself to analysis. Therefore, the relationship of vowel length before voiced and voiceless consonants to the foreign accent scores could not be determined. 


\section{Voice Onset Time}

The VOT shift measures how many times longer the VOT in stressed syllables is than that in unstressed syllables. The VOT shifts for each speaker are shown in Table 4.

The range of native English speakers' VOT shifts shows that VOT was 1.70 to 2.86 times longer in stressed syllables than in unstressed ones. The native Spanish speakers' VOT shifts ranged more widely, from .87 to 2.82 . The VOT shift was found to be significantly correlated with the foreign accent scores $(r=-.62, p<.01)$.

Past research shows that VOT values shorter than those in the native range are significantly correlated with the perception of foreign accent (Major, 1987; Riney and Takagi, 1999). Flege (1991) also reports that, while the native Spanish speakers used in his study tended to produce short VOT values, some learners (the ones who began learning English at an earlier age) could produce native-like VOT values. The present study upholds these findings. The VOT values were found to be significantly correlated with the foreign accent scores. Furthermore, the native Spanish speakers were found to produce VOT values that ranged from well below the native range to the upper end of the native range, indicating that some native Spanish speakers did produce native-like VOT values.

\section{$\underline{\text { Segmental Accuracy }}$}

The segmental accuracy score equals the total number of segmental errors, a higher score indicating more errors. The segmental accuracy scores for each speaker are reported in Table 5.

The range of segmental accuracy scores for the native English speakers was from 0 to 5. The native Spanish speakers' scores, however, ranged from 2 to 44, clearly illustrating the drastic difference in segmental accuracy between the two groups. The 
relationship between the segmental accuracy scores and the foreign accent scores was very strong $(r=.92)$ and highly significant $(\mathrm{p}<.001)$. This result is the average of the three raters' individual correlations, which ranged from $r=.91$ to .93 .

These findings are similar to those reported by Brennan, Ryan and Dawson (1997, as cited in Flege, 1981), Munro and Derwing (1995) and Magen (1998) who found that segmental errors are significantly correlated with foreign accent ratings. Derwing and Munro (1997), however, found that segmental errors were significantly correlated with foreign accent scores for only four of their twenty six listeners. Two differences between the present study and the Derwing and Munro study may account for this disagreement. First, Derwing and Munro used speakers of Cantonese, Japanese, Polish, and Spanish. As the present study involved only Spanish speakers, it is reasonable to propose that native language may have some effect on the importance of segmental errors in foreign accent perception and that the two studies are therefore incomparable. Second, Derwing and Munro defined segmental errors as deletions, substitutions, and insertions. The present study added segmental distortions to their definition. The differing definitions of segmental error may also partially account for the contradictory findings. 


\section{Table 5}

$\underline{\text { Segmental Accuracy }}$

\begin{tabular}{|c|c|c|c|}
\hline \multirow[t]{2}{*}{ Speaker } & \multicolumn{3}{|c|}{ Segmental Accuracy Scores $=$ total errors } \\
\hline & rater: 1 & 2 & 3 \\
\hline 1 & 12 & 26 & 14 \\
\hline 2 & 15 & 44 & 29 \\
\hline 3 & 22 & 34 & 26 \\
\hline 4 & 13 & 25 & 14 \\
\hline 5 & 11 & 18 & 14 \\
\hline 6 & 12 & 9 & 15 \\
\hline 7 & 16 & 22 & 14 \\
\hline 8 & 17 & 22 & 12 \\
\hline 9 & 21 & 29 & 21 \\
\hline 10 & 2 & 1 & $\mathbf{0}$ \\
\hline 11 & 2 & 1 & 0 \\
\hline 12 & 2 & $\mathbf{0}$ & $\mathbf{0}$ \\
\hline 13 & 14 & 18 & 12 \\
\hline 14 & $\mathbf{0}$ & $\mathbf{0}$ & $\mathbf{0}$ \\
\hline 15 & 14 & 22 & 10 \\
\hline 16 & 18 & 23 & 20 \\
\hline 17 & 9 & 15 & 13 \\
\hline 18 & 15 & 26 & 16 \\
\hline 21 & 2 & 6 & 5 \\
\hline 22 & 5 & $\mathbf{0}$ & $\mathbf{0}$ \\
\hline 23 & 0 & 0 & 0 \\
\hline 24 & 0 & 1 & $\mathbf{0}$ \\
\hline
\end{tabular}

Note. Native English speakers are in bold. 


\section{Chapter 5}

Summary

The purpose of the present study was to determine which of the investigated speech-related variables influences the degree of perceived foreign accent most heavily. The variables considered in the study were intonation; the intensity, duration, and fundamental frequency (fo) of stressed vowels; the voice onset time (VOT) of voiceless stops; and segmental accuracy.

Recorded speech samples of six native speakers of English and fifteen native speakers of Spanish were presented to nineteen native English speaking listeners. The listeners rated the speech samples for comprehensibility and degree of foreign accent.

The speech samples were analyzed spectrographically to obtain numerical values for intonation, the three parameters of stress, and VOT. Segmental accuracy was determined by the author's auditory analysis of the speech samples.

Statistical procedures showed that three variables were significantly correlated with the average foreign accent score assigned by the listeners: the length of stressed vowels, VOT, and segmental accuracy. Segmental accuracy had, by far, the most significant effect on the foreign accent scores. Intonation and the frequency and intensity of stressed vowels were not found to be significantly correlated with the foreign accent scores.

\section{$\underline{\text { Limitations }}$}

The following limitation applies to the present study:

1. The effect of vowel length before voiced and voiceless consonants on the foreign accent scores could not be determined. 


\section{Conclusions}

Despite the study's inherent limitations, the following conclusions are proposed:

1. Segmental accuracy exerts the strongest effect on the degree of foreign accent perceived by native English speakers from West Virginia University in the speech of native Spanish speakers when investigated in conjunction with intonation, stress, and VOT.

2. VOT and the length of stressed vowels also exert significant effects on the degree of perceived foreign accent under the same conditions.

These conclusions are important for researchers, speech clinicians and teachers. Researchers trying to account for differences in foreign accent ratings among nonnative English speakers now have further information about which speech-related variables native English speakers attend to when asked to rate foreign accents. Clinicians and teachers are often in contact with nonnative speakers who would like to reduce their degree of foreign accent. They too can keep the present findings in mind when deciding the most efficient approach to reducing foreign accent.

\section{$\underline{\text { Suggestions for Further Research }}$}

A larger, more extensive, version of the present study would serve to support or refute the present findings. It is recommended that future investigations include random samples of native and nonnative speakers and of native English speaking listeners to allow for further statistical analysis. It would also be helpful for future research in the field to employ reading material used in earlier studies so that comparisons could be more easily drawn. 


\section{References}

Anderson-Hsieh, J., and Koehler, K. (1988). The effect of foreign accent and speaking rate on native speaker comprehension. Language Learning, 38:4, 561-613.

Anderson-Hsieh, J., Johnson, R., and Koehler, K. (1992). The relationship between native speaker judgments of nonnative pronunciation and deviance in segmentals, prosody, and syllable structure. Language Learning, 42:4, 529-555.

Avery, P., and Ehrlich, S. (1992) Teaching American English Pronunciation. Oxford: Oxford University Press.

Catford, J. (1977). Fundamental Problems in Phonetics. Bloomington: Indiana University Press.

Chreist, F. (1964). Foreign Accent. Englewood Cliffs, NJ: Prentice Hall.

Couper-Kuhlen, E. (1986). Introduction to English Prosody. London: Edward Arnold.

Delattre, P. (1969). An acoustic and articulatory study of vowel reduction in four languages. IRAL, 7:4, 295-325.

Derwing, T., and Munro, M. (1997). Accent, intelligibility, and comprehensibility. Studies in Second Language Acquisition, 19, 1-16.

Fairbanks, G. (1960). Voice and Articulation Drillbook. New York: Harper and Row.

Flege, J. (1981). The phonological basis of foreign accent: a hypothesis. TESOL Quarterly, 15:4, 443-455.

Flege, J. (1984). The detection of French accent by American listeners. Journal of the Acoustical Society of America, 76:3, 692-707.

Flege, J. (1987). The instrumental study of L2 speech production: some methodological considerations. Language Learning, 37:2, 285-296.

Flege, J. (1988). Using visual information to train foreign-language vowel production. 
Language Learning, 38:3, 365-xxx.

Flege, J. (1993). Production and perception of a novel, second-language phonetic contrast. Journal of the Acoustical Society of America, 93:3, 1589-1608.

Flege, J., Frieda, E., Walley, A., and Randazza, L. (1998). Lexical factors and segmental accuracy in second language speech production. Studies in Second Language Acquisition, 20, 155-187.

Fokes, J., and Bond, Z. (1989). The vowels of stressed and unstressed syllables in nonnative English. Language Learning, 39:3, 341-371.

Hatch, E., and Lazaraton, A. (1991). The Research Manual: Design and Statistics for Applied Linguistics. New York: Newbury House.

Kent, R., Dembowski, J., and Lass, N. (1996). The acoustic characteristics of American English. In Lass, N. (ed.), Principles of Experimental Phonetics. St. Louis: Mosby, $185-225$.

Ladefoged, P. (1975). A course in phonetics. Atlanta: Harcourt Brace Jovanovich, Inc.

Lehiste, I. (1970). Suprasegmentals. Cambridge, MA: The MIT Press.

Lehiste, I. (1996). Suprasegmental features of speech. In Lass, N. (ed.), Principles of Experimental Phonetics. St. Louis: Mosby, 227-243.

Magen, H. (1998). The perception of foreign-accented speech. Journal of Phonetics, 26, $381-400$.

Major, R. (1987). English voiceless stop production by speakers of Brazilian Portuguese. Journal of Phonetics, 15, 197-202.

Munro, M. (1995). Nonsegmental factors in foreign accent. Studies in Second Language Acquisition, 17, 17-34.

Munro, M., and Derwing, T. (1995). Foreign accent, comprehensibility, and intelligibility 
in the speech of second language learners. Language Learning, 45:1, 73-97.

Nooteboom, S. (1997). The prosody of speech: melody and rhythm. In Hardcastle, W., and Laver, J. (eds.), The Handbook of Phonetic Sciences. Cambridge: Blackwell Publishers, Inc.

Peterson, G., and Lehiste, I. (1960). Duration of syllable nuclei in English. Journal of the Acoustical Society of America, 32:6, 693-703.

Riney, T., and Flege, J. (1998). Changes over time in global foreign accent and liquid identifiability and accuracy. Studies in Second Language Acquisition, 20, 213243.

Riney, T., and Takagi, N. (1999). Global foreign accent and voice onset time among Japanese EFL speakers. Language Learning, 49:2, 275-302.

'THart, J. (1984). A phonetic approach to intonation: from pitch contours to intonation patterns. Intonation, Accent, and Rhythm. New York: Walter de Gruyter.

Van Els, T., and De Bot, K. (1987). The role of intonation in foreign accent. Modern Language Journal, 71:2, 147-155. 


\section{Appendix A}

\section{The Paper Doll}

She was cutting the thick paper with huge scissors when Joe chose to offer her some help. He wasn't obligated to help her, but the five year old girl's hand was so small and the scissors were so big that he decided it would be friendly to ask if she wanted help. She accepted Joe's offer. He took the scissors while she continued to hold the half-cut sheet of paper. She said she planned to make a life-size paper doll to use as a toy. Joe wondered how she could do that with one piece of paper that measured eleven inches in length. 


\section{Appendix B}

Speakers

\section{$\underline{\text { Instructions to Speakers }}$}

I am studying speakers' speech characteristics so please talk in your normal manner. Your speech will be recorded onto an audio tape. Your participation in this study is totally voluntary, and your performance will be kept strictly confidential and anonymous. In addition, your willingness to participate or not participate will have no effect on your grade or class standing in any class. Moreover, if you are a member of a sports team, your team status will not be affected by your willingness or unwillingness to participate in this study. Although you do not have to participate in every task, I would certainly appreciate it.

Reading Task

Please read the passages silently to familiarize yourself with the wording. Then read them out loud in your normal manner while I record you. You may be asked to read them again. Are there any questions?

Impromptu Speech Task

Please choose a picture and make an impromptu speech about that picture. You may be asked to choose a second or third picture for further speeches. Are there any questions? Thank you for your cooperation! This study is being conducted as part of my master's thesis in partial fulfillment of the requirements for an MA in Linguistics. 


\section{Native Spanish Speaker Background Questionnaire}

What city and country are you from originally?

Other than your native country and the United States, where else have you lived?

Other than Spanish and English, what languages have you studied or do you speak?

Do any members of your family speak English? circle one: yes no

If so, who? (mother, brother, etc.)

Do you speak English in your home in your native country?

circle one: often sometimes never

Do you speak English in your home in the United States?

circle one: often sometimes never

How long have you been in the United States?

How long have you been in West Virginia?

Where else in the United States have you lived for more than two weeks in a row?

Have you ever formally studied American English? If so, for how long?

Was your teacher a native speaker of American English?

$$
\text { circle one: yes no don't know }
$$

Have you ever formally studied British English? If so, for how long?

Was your teacher a native speaker of British English?

$$
\text { circle one: yes no don't know }
$$

At what age did you start studying English (any variety)?

How often do you hear English in your native country?

$$
\text { circle one: often sometimes never }
$$

If sometimes or often, in what environments? (on $\mathrm{TV}$, on the radio, etc.)

On a scale of 1-7 where 1 means no foreign accent and 7 means a heavy foreign accent, 
how would you rate your Spanish accent when you speak English? Place an X in the appropriate box.

$\begin{array}{lllllllll}\text { no foreign } & 1 & 2 & 3 & 4 & 5 & 6 & 7 & \text { heavy foreign } \\ \text { accent } & \square & \square & \square & \square & \square & \square & \square & \text { accent }\end{array}$

If you think you have an accent, would you like to change the way you sound in English if you could or do you like your accent? (Please use the back if you need more room.) 


\section{Native English Speaker Background Questionnaire}

What city and county are you from originally?

Where else have you lived and for how long?

Other than English, what languages have you studied or do you speak?

How old were you when you began learning another language?

How long did you study the other languages?

How well would you say you speak the other languages?

If you studied with a teacher, was your teacher a native speaker of the other language?

Does anyone in your family speak a language other than American English?

If so, please state what language and who speaks it. (ie. my grandmother speaks Russian)

When you were young (birth - before college) were you ever exposed to people who speak another language or speak English with any sort of foreign accent? What language(s)/accent(s) were you exposed to at what age, and how often?

Do you think that the way you speak is representative of the way people speak in the area in which you live? If not, why not?

Have you ever been diagnosed with a speech, language, or hearing problem?

If so, do you think this problem affects your pronunciation now?

Do you think you may have a speech, language, or hearing problem?

Please make any additional comments you think are relevant to the way you speak English. 


\section{Appendix C \\ Listening Sessions \\ $\underline{\text { Instructions to Listeners }}$}

Dear Subject,

I am interested in your perception of speakers. Your participation in this study is totally voluntary, and your responses will be kept strictly confidential and anonymous. In addition, your willingness to participate or not participate will have no effect on your grade or class standing in any class. Moreover, if you are a member of a sports team, your team status will not be affected by your willingness or unwillingness to participate in this study. Although you do not have to participate in every task, I would certainly appreciate it.

You will hear samples of people speaking. Please listen carefully to each speaker. For each speaker you will complete a rating scale by placing an $\mathrm{X}$ in the appropriate box. First you will rate the speakers on a scale of 1 to 7 where 1 means completely comprehensible and 7 means completely incomprehensible. After this task you will hear the speakers again. This time you will rate the speakers on a scale of 1-7 where 1 means no foreign accent at all and 7 means heavily foreign accented. On each scale, a rating of 4 indicates a neutral response.

Here is an example. If you think a speaker is mostly comprehensible and barely has a foreign accent, your ratings would be as follows:

$\begin{array}{lllllllll}\text { completely } & 1 & 2 & 3 & 4 & 5 & 6 & 7 & \text { completely } \\ \text { comprehensible } & \square & \square & \mathrm{X} & \square & \square & \square & \square & \text { incomprehensible } \\ \text { no foreign } & 1 & 2 & 3 & 4 & 5 & 6 & 7 & \text { heavy foreign } \\ \text { accent } & \square & \mathrm{X} & \square & \square & \square & \square & \square\end{array}$

Thank you for your cooperation! This study is being conducted as part of my master's thesis in partial fulfillment of the requirements for an MA in Linguistics. 
Speaker 1

Comprehensibility Rating Form

$\begin{array}{lllllllll}\text { completely } & 1 & 2 & 3 & 4 & 5 & 6 & 7 & \text { completely } \\ \text { comprehensible } & \square & \square & \square & \square & \square & \square & \square & \text { incomprehensible }\end{array}$

Speaker 2

$\begin{array}{llllllllll}\text { completely } & 1 & 2 & 3 & 4 & 5 & 6 & 7 & \text { completely }\end{array}$

comprehensible $\square \quad \square \quad \square \quad \square \quad \square \quad \square \quad \square \quad \square$ incomprehensible

Speaker 3

$\begin{array}{llllllllll}\text { completely } & 1 & 2 & 3 & 4 & 5 & 6 & 7 & \text { completely }\end{array}$

comprehensible $\square \quad \square \quad \square \quad \square \quad \square \quad \square \quad \square \quad \square$ incomprehensible

Speaker 4

$\begin{array}{lllllllll}\text { completely } & 1 & 2 & 3 & 4 & 5 & 6 & 7 & \text { completely }\end{array}$

comprehensible $\quad \square \quad \square \quad \square \quad \square \quad \square \quad \square \quad \square$ incomprehensible

Speaker 5

$\begin{array}{lllllllll}\text { completely } & 1 & 2 & 3 & 4 & 5 & 6 & 7 & \text { completely } \\ \text { comprehensible } & \square & \square & \square & \square & \square & \square & \square \text { incomprehensible }\end{array}$

Speaker 6

$\begin{array}{lllllllll}\text { completely } & 1 & 2 & 3 & 4 & 5 & 6 & 7 & \text { completely }\end{array}$

comprehensible $\square \quad \square \quad \square \quad \square \quad \square \quad \square \quad \square$ incomprehensible

Speaker 7

$\begin{array}{llllllllll}\text { completely } & 1 & 2 & 3 & 4 & 5 & 6 & 7 & \text { completely }\end{array}$

comprehensible $\square \quad \square \quad \square \quad \square \quad \square \quad \square \quad \square$ incomprehensible

Speaker 8

$\begin{array}{lllllllll}\text { completely } & 1 & 2 & 3 & 4 & 5 & 6 & 7 & \text { completely }\end{array}$

comprehensible $\square \quad \square \quad \square \quad \square \quad \square \quad \square \quad \square$ incomprehensible

Speaker 9

$\begin{array}{llllllllll}\text { completely } & 1 & 2 & 3 & 4 & 5 & 6 & 7 & \text { completely }\end{array}$

comprehensible $\square \quad \square \quad \square \quad \square \quad \square \quad \square \quad \square$ incomprehensible

Speaker 10

$\begin{array}{lllllllll}\text { completely } & 1 & 2 & 3 & 4 & 5 & 6 & 7 & \text { completely }\end{array}$

comprehensible $\square \quad \square \quad \square \quad \square \quad \square \quad \square \quad \square$ incomprehensible

Speaker 11

$\begin{array}{lllllllll}\text { completely } & 1 & 2 & 3 & 4 & 5 & 6 & 7 & \text { completely } \\ \text { comprehensible } & \square & \square & \square & \square & \square & \square & \square & \text { incomprehensible }\end{array}$

Speaker 12

$\begin{array}{llllllllll}\text { completely } & 1 & 2 & 3 & 4 & 5 & 6 & 7 & \text { completely }\end{array}$

comprehensible $\square \quad \square \quad \square \quad \square \quad \square \quad \square \quad \square$ incomprehensible

Speaker 13

$\begin{array}{llllllllll}\text { completely } & 1 & 2 & 3 & 4 & 5 & 6 & 7 & \text { completely }\end{array}$

comprehensible $\square \quad \square \quad \square \quad \square \quad \square \quad \square \quad \square$ incomprehensible 
Speaker 14

$\begin{array}{lllllllll}\text { completely } & 1 & 2 & 3 & 4 & 5 & 6 & 7 & \text { completely } \\ \text { comprehensible } & \square & \square & \square & \square & \square & \square & \square & \text { incomprehensible }\end{array}$

Speaker 15

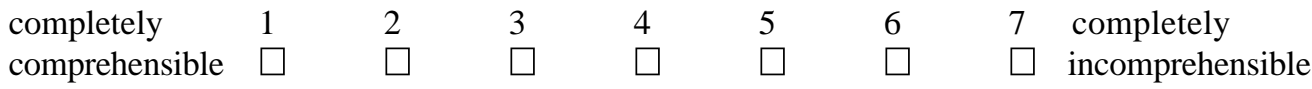

Speaker 16

$\begin{array}{lllllllll}\text { completely } & 1 & 2 & 3 & 4 & 5 & 6 & 7 & \text { completely } \\ \text { comprehensible } & \square & \square & \square & \square & \square & \square & \square \text { incomprehensible }\end{array}$

Speaker 17

$\begin{array}{lllllllll}\text { completely } & 1 & 2 & 3 & 4 & 5 & 6 & 7 & \text { completely } \\ \text { comprehensible } & \square & \square & \square & \square & \square & \square & \square \text { incomprehensible }\end{array}$

Speaker 18

$\begin{array}{lllllllll}\text { completely } & 1 & 2 & 3 & 4 & 5 & 6 & 7 & \text { completely } \\ \text { comprehensible } & \square & \square & \square & \square & \square & \square & \square & \text { incomprehensible }\end{array}$

Speaker 19

$\begin{array}{llllllllll}\text { completely } & 1 & 2 & 3 & 4 & 5 & 6 & 7 & \text { completely }\end{array}$

comprehensible $\square \quad \square \quad \square \quad \square \quad \square \quad \square \quad \square \quad$ incomprehensible

Speaker 20

$\begin{array}{lllllllll}\text { completely } & 1 & 2 & 3 & 4 & 5 & 6 & 7 & \text { completely }\end{array}$

comprehensible $\square \quad \square \quad \square \quad \square \quad \square \quad \square \quad \square$ incomprehensible

Speaker 21

$\begin{array}{llllllllll}\text { completely } & 1 & 2 & 3 & 4 & 5 & 6 & 7 & \text { completely }\end{array}$

comprehensible $\square \quad \square \quad \square \quad \square \quad \square \quad \square \quad \square$ incomprehensible

Speaker 22

$\begin{array}{lllllllll}\text { completely } & 1 & 2 & 3 & 4 & 5 & 6 & 7 & \text { completely }\end{array}$

comprehensible $\square \quad \square \quad \square \quad \square \quad \square \quad \square \quad \square$ incomprehensible

Speaker 23

$\begin{array}{lllllllll}\text { completely } & 1 & 2 & 3 & 4 & 5 & 6 & 7 & \text { completely } \\ \text { comprehensible } & \square & \square & \square & \square & \square & \square & \square \text { incomprehensible }\end{array}$

Speaker 24

$\begin{array}{lllllllll}\text { completely } & 1 & 2 & 3 & 4 & 5 & 6 & 7 & \text { completely }\end{array}$

comprehensible $\quad \square \quad \square \quad \square \quad \square \quad \square \quad \square \quad \square \quad \square$ incomprehensible

Speaker 25

$\begin{array}{lllllllll}\text { completely } & 1 & 2 & 3 & 4 & 5 & 6 & 7 & \text { completely } \\ \text { comprehensible } & \square & \square & \square & \square & \square & \square & \square \text { incomprehensible }\end{array}$

Speaker 26

$\begin{array}{lllllllll}\text { completely } & 1 & 2 & 3 & 4 & 5 & 6 & 7 & \text { completely } \\ \text { comprehensible } & \square & \square & \square & \square & \square & \square & \square \text { incomprehensible }\end{array}$


Speaker 27

$\begin{array}{lllllllll}\text { completely } & 1 & 2 & 3 & 4 & 5 & 6 & 7 & \text { completely } \\ \text { comprehensible } & \square & \square & \square & \square & \square & \square & \square & \text { incomprehensible }\end{array}$

Speaker 28

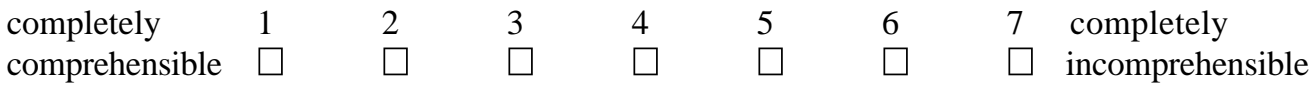

Speaker 29

$\begin{array}{lllllllll}\text { completely } & 1 & 2 & 3 & 4 & 5 & 6 & 7 & \text { completely } \\ \text { comprehensible } & \square & \square & \square & \square & \square & \square & \square \text { incomprehensible }\end{array}$

Speaker 30

$\begin{array}{lllllllll}\text { completely } & 1 & 2 & 3 & 4 & 5 & 6 & 7 & \text { completely } \\ \text { comprehensible } & \square & \square & \square & \square & \square & \square & \square & \text { incomprehensible }\end{array}$

Speaker 31

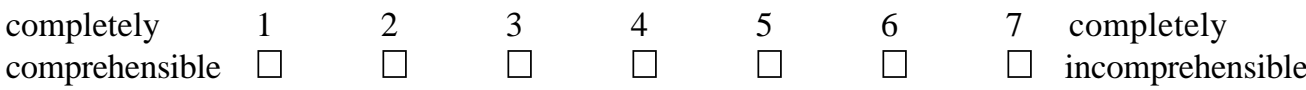

Speaker 32

$\begin{array}{lllllllll}\text { completely } & 1 & 2 & 3 & 4 & 5 & 6 & 7 & \text { completely }\end{array}$

comprehensible $\square \quad \square \quad \square \quad \square \quad \square \quad \square \quad \square$ incomprehensible

Speaker 33

$\begin{array}{lllllllll}\text { completely } & 1 & 2 & 3 & 4 & 5 & 6 & 7 & \text { completely }\end{array}$

comprehensible $\square \quad \square \quad \square \quad \square \quad \square \quad \square \quad \square$ incomprehensible

\begin{tabular}{|c|c|c|c|c|c|c|c|c|c|}
\hline Speaker & $\begin{array}{l}34 \\
\text { completely } \\
\text { comprehensible }\end{array}$ & $\begin{array}{l}1 \\
\square\end{array}$ & $\begin{array}{l}2 \\
\square\end{array}$ & $\begin{array}{l}3 \\
\square\end{array}$ & $\begin{array}{l}4 \\
\square\end{array}$ & $\begin{array}{l}5 \\
\square\end{array}$ & $\begin{array}{l}6 \\
\square\end{array}$ & $\begin{array}{l}7 \\
\square\end{array}$ & $\begin{array}{l}\text { completely } \\
\text { incomprehensible }\end{array}$ \\
\hline Speaker & & & & & & & & & \\
\hline & completely & 1 & 2 & 3 & 4 & 5 & 6 & 7 & completely \\
\hline & comprehensible & $\square$ & $\square$ & $\square$ & $\square$ & $\square$ & $\square$ & $\square$ & incomprehensible \\
\hline Speaker & & & & & & & & & \\
\hline & completely & 1 & 2 & 3 & 4 & 5 & 6 & 7 & completely \\
\hline & comprehensible & $\square$ & $\square$ & $\square$ & $\square$ & $\square$ & $\square$ & $\square$ & incomprehensible \\
\hline Speaker & & & & & & & & & \\
\hline & completely & 1 & 2 & 3 & 4 & 5 & 6 & 7 & completely \\
\hline & comprehensible & $\square$ & $\square$ & $\square$ & $\square$ & $\square$ & $\square$ & $\square$ & incomprehensible \\
\hline Speaker & & & & & & & & & \\
\hline & completely & 1 & 2 & 3 & 4 & 5 & 6 & 7 & completely \\
\hline & comprehensible & $\square$ & $\square$ & $\square$ & $\square$ & $\square$ & $\square$ & $\square$ & incomprehensible \\
\hline Speaker & & & & & & & & & \\
\hline & completely & 1 & 2 & 3 & 4 & 5 & 6 & 7 & completely \\
\hline & comprehensible & $\square$ & $\square$ & $\square$ & $\square$ & $\square$ & $\square$ & $\square$ & incomprehensible \\
\hline
\end{tabular}


Speaker 40

$\begin{array}{lllllllll}\text { completely } & 1 & 2 & 3 & 4 & 5 & 6 & 7 & \text { completely } \\ \text { comprehensible } & \square & \square & \square & \square & \square & \square & \square \text { incomprehensible }\end{array}$

\begin{tabular}{|c|c|c|c|c|c|c|c|c|}
\hline $\begin{aligned} \text { Speaker } & 41 \\
& \text { completely } \\
& \text { comprehensible }\end{aligned}$ & $\begin{array}{l}1 \\
\square\end{array}$ & $\begin{array}{l}2 \\
\square\end{array}$ & $\begin{array}{l}3 \\
\square\end{array}$ & $\begin{array}{l}4 \\
\square\end{array}$ & $\begin{array}{l}5 \\
\square\end{array}$ & $\begin{array}{l}6 \\
\square\end{array}$ & $\begin{array}{l}7 \\
\square\end{array}$ & $\begin{array}{l}\text { completely } \\
\text { incomprehensible }\end{array}$ \\
\hline $\begin{aligned} \text { Speaker } & 42 \\
& \text { completely } \\
& \text { comprehensible }\end{aligned}$ & $\begin{array}{l}1 \\
\square\end{array}$ & $\begin{array}{l}2 \\
\square\end{array}$ & $\begin{array}{l}3 \\
\square\end{array}$ & $\begin{array}{l}4 \\
\square\end{array}$ & $\begin{array}{l}5 \\
\square\end{array}$ & $\begin{array}{l}6 \\
\square\end{array}$ & $\begin{array}{l}7 \\
\square\end{array}$ & $\begin{array}{l}\text { completely } \\
\text { incomprehensible }\end{array}$ \\
\hline $\begin{aligned} \text { Speaker } & 43 \\
& \text { completely } \\
& \text { comprehensible }\end{aligned}$ & $\begin{array}{l}1 \\
\square\end{array}$ & $\begin{array}{l}2 \\
\square\end{array}$ & $\begin{array}{l}3 \\
\square\end{array}$ & $\begin{array}{l}4 \\
\square\end{array}$ & $\begin{array}{l}5 \\
\square\end{array}$ & $\begin{array}{l}6 \\
\square\end{array}$ & $\begin{array}{l}7 \\
\square\end{array}$ & $\begin{array}{l}\text { completely } \\
\text { incomprehensible }\end{array}$ \\
\hline $\begin{aligned} \text { Speaker } & 44 \\
& \text { completely } \\
& \text { comprehensible }\end{aligned}$ & $\begin{array}{l}1 \\
\square\end{array}$ & $\begin{array}{l}2 \\
\square\end{array}$ & $\begin{array}{l}3 \\
\square\end{array}$ & $\begin{array}{l}4 \\
\square\end{array}$ & $\begin{array}{l}5 \\
\square\end{array}$ & $\begin{array}{l}6 \\
\square\end{array}$ & $\begin{array}{l}7 \\
\square\end{array}$ & $\begin{array}{l}\text { completely } \\
\text { incomprehensible }\end{array}$ \\
\hline
\end{tabular}




\begin{tabular}{|c|c|c|c|c|c|c|c|c|c|}
\hline \multirow{2}{*}{ Speaker } & \multicolumn{9}{|c|}{ Foreign Accent Rating Form } \\
\hline & $\begin{array}{l}1 \\
\text { no foreign } \\
\text { accent }\end{array}$ & $\begin{array}{l}1 \\
\square\end{array}$ & $\begin{array}{l}2 \\
\square\end{array}$ & $\begin{array}{l}3 \\
\square\end{array}$ & $\begin{array}{l}4 \\
\square\end{array}$ & $\begin{array}{l}5 \\
\square\end{array}$ & $\begin{array}{l}6 \\
\square\end{array}$ & $\begin{array}{l}7 \\
\square\end{array}$ & $\begin{array}{l}\text { heavy foreign } \\
\text { accent }\end{array}$ \\
\hline \multicolumn{10}{|c|}{ Speaker 2} \\
\hline & no foreign & 1 & 2 & 3 & 4 & 5 & 6 & 7 & heavy foreign \\
\hline & accent & $\square$ & $\square$ & $\square$ & $\square$ & $\square$ & $\square$ & $\square$ & accent \\
\hline \multicolumn{10}{|c|}{ Speaker 3} \\
\hline & no foreign & 1 & 2 & 3 & 4 & 5 & 6 & 7 & heavy foreign \\
\hline & accent & $\square$ & $\square$ & $\square$ & $\square$ & $\square$ & $\square$ & $\square$ & accent \\
\hline \multicolumn{10}{|c|}{ Speaker 4} \\
\hline & no foreign & 1 & 2 & 3 & 4 & 5 & 6 & 7 & heavy foreign \\
\hline & accent & $\square$ & $\square$ & $\square$ & $\square$ & $\square$ & $\square$ & $\square$ & accent \\
\hline \multicolumn{10}{|c|}{ Speaker 5} \\
\hline & no foreign & 1 & 2 & 3 & 4 & 5 & 6 & 7 & heavy foreign \\
\hline & accent & $\square$ & $\square$ & $\square$ & $\square$ & $\square$ & $\square$ & $\square$ & accent \\
\hline \multicolumn{10}{|c|}{ Speaker 6} \\
\hline & no foreign & 1 & 2 & 3 & 4 & 5 & 6 & 7 & heavy foreign \\
\hline & accent & $\square$ & $\square$ & $\square$ & $\square$ & $\square$ & $\square$ & $\square$ & accent \\
\hline \multicolumn{10}{|c|}{ Speaker 7} \\
\hline & no foreign & 1 & 2 & 3 & 4 & 5 & 6 & 7 & heavy foreign \\
\hline & accent & $\square$ & $\square$ & $\square$ & $\square$ & $\square$ & $\square$ & $\square$ & accent \\
\hline \multicolumn{10}{|c|}{ Speaker 8} \\
\hline & no foreign & 1 & 2 & 3 & 4 & 5 & 6 & 7 & heavy foreign \\
\hline & accent & $\square$ & $\square$ & $\square$ & $\square$ & $\square$ & $\square$ & $\square$ & accent \\
\hline \multicolumn{10}{|c|}{ Speaker 9} \\
\hline & no foreign & 1 & 2 & 3 & 4 & 5 & 6 & 7 & heavy foreign \\
\hline & accent & $\square$ & $\square$ & $\square$ & $\square$ & $\square$ & $\square$ & $\square$ & accent \\
\hline \multicolumn{10}{|c|}{ Speaker 10} \\
\hline & no foreign & 1 & 2 & 3 & 4 & 5 & 6 & 7 & heavy foreign \\
\hline & accent & $\square$ & $\square$ & $\square$ & $\square$ & $\square$ & $\square$ & $\square$ & accent \\
\hline \multicolumn{10}{|c|}{ Speaker 11} \\
\hline & no foreign & 1 & 2 & 3 & 4 & 5 & 6 & 7 & heavy foreign \\
\hline & accent & $\square$ & $\square$ & $\square$ & $\square$ & $\square$ & $\square$ & $\square$ & accent \\
\hline \multicolumn{10}{|c|}{ Speaker 12} \\
\hline & no foreign & 1 & 2 & 3 & 4 & 5 & 6 & 7 & heavy foreign \\
\hline & accent & $\square$ & $\square$ & $\square$ & $\square$ & $\square$ & $\square$ & $\square$ & accent \\
\hline \multicolumn{10}{|c|}{ Speaker 13} \\
\hline & no foreign & 1 & 2 & 3 & 4 & 5 & 6 & 7 & heavy foreign \\
\hline & & & & & & & & $\square$ & \\
\hline
\end{tabular}


Speaker 14

$\begin{array}{lllllllll}\text { no foreign } & 1 & 2 & 3 & 4 & 5 & 6 & 7 & \text { heavy foreign }\end{array}$ accent

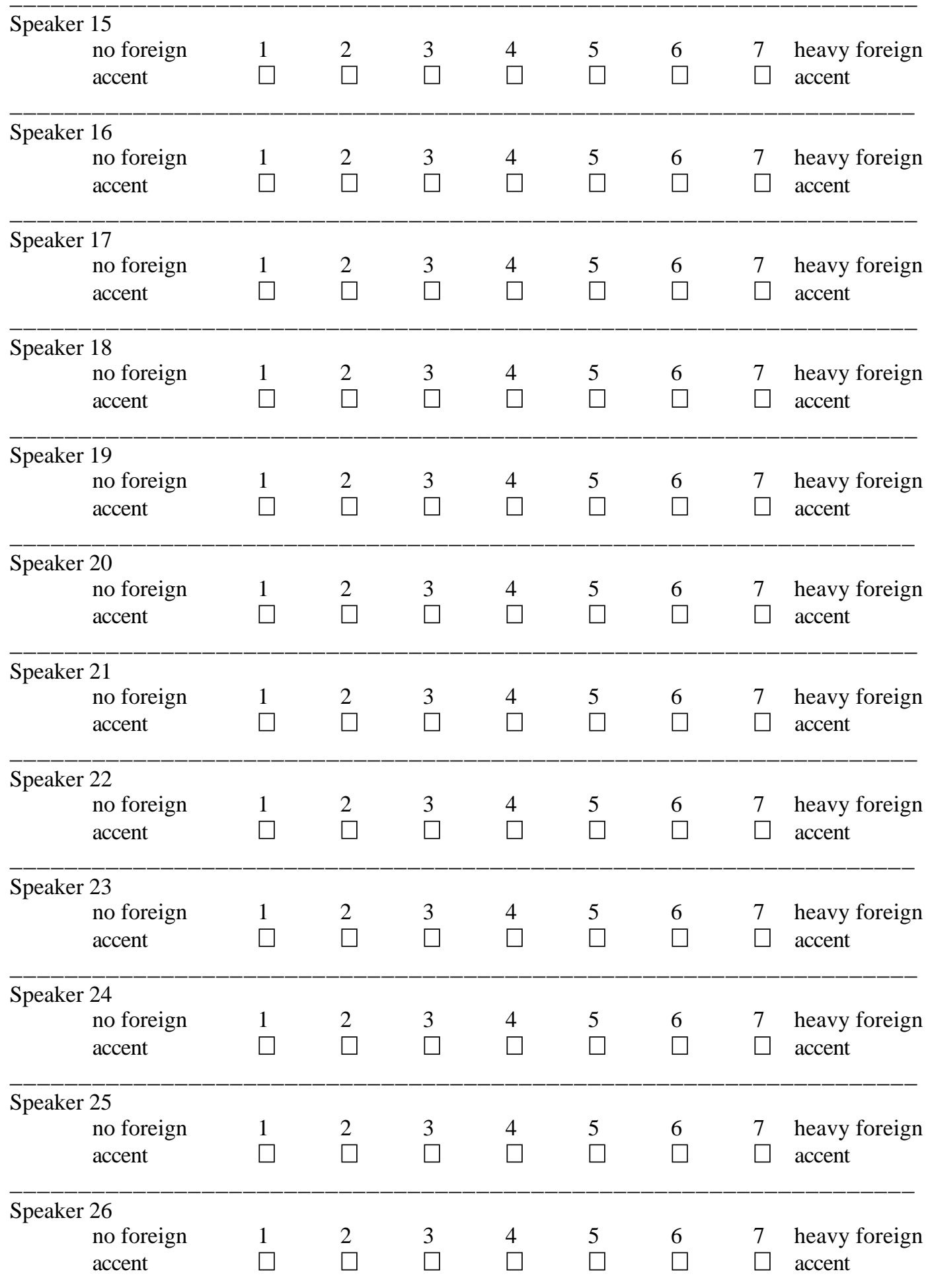


Speaker 27

$\begin{array}{lllllllll}\text { no foreign } & 1 & 2 & 3 & 4 & 5 & 6 & 7 & \text { heavy foreign }\end{array}$ accent

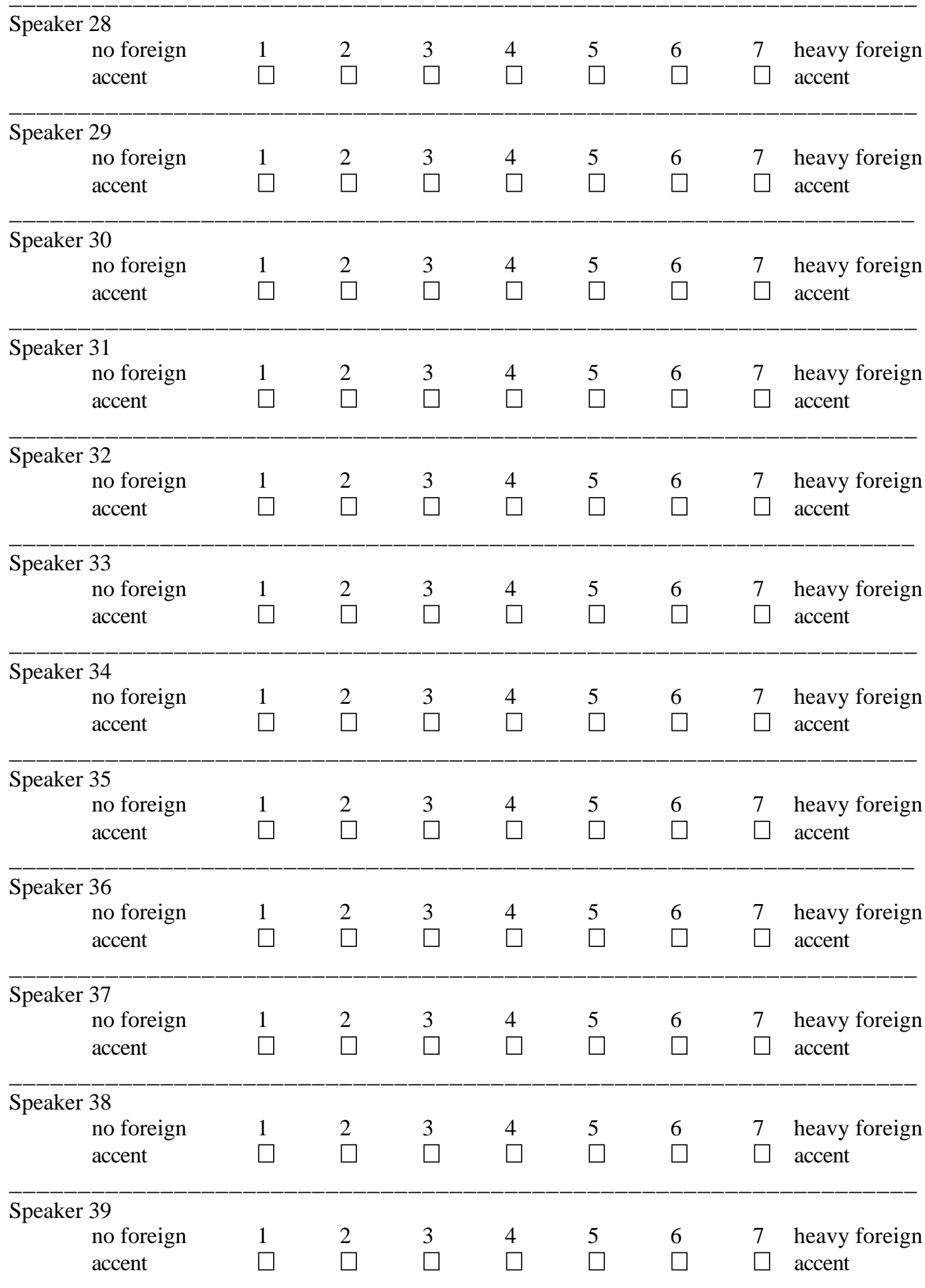


Speaker 40

$\begin{array}{lllllllll}\text { no foreign } & 1 & 2 & 3 & 4 & 5 & 6 & 7 & \text { heavy foreign } \\ \text { accent } & \square & \square & \square & \square & \square & \square & \square\end{array}$

\begin{tabular}{|c|c|c|c|c|c|c|c|c|}
\hline \multicolumn{9}{|l|}{ Speaker 41} \\
\hline no foreign & 1 & 2 & 3 & 4 & 5 & 6 & 7 & heavy foreign \\
\hline accent & $\square$ & $\square$ & $\square$ & $\square$ & $\square$ & $\square$ & $\square$ & accent \\
\hline \multicolumn{9}{|l|}{ Speaker 42} \\
\hline no foreign & 1 & 2 & 3 & 4 & 5 & 6 & 7 & heavy foreign \\
\hline accent & $\square$ & $\square$ & $\square$ & $\square$ & $\square$ & $\square$ & $\square$ & accent \\
\hline \multicolumn{9}{|l|}{ Speaker 43} \\
\hline no foreign & 1 & 2 & 3 & 4 & 5 & 6 & 7 & heavy foreign \\
\hline accent & $\square$ & $\square$ & $\square$ & $\square$ & $\square$ & $\square$ & $\square$ & accent \\
\hline \multicolumn{9}{|l|}{ Speaker 44} \\
\hline no foreign & 1 & 2 & 3 & 4 & 5 & 6 & 7 & heavy foreign \\
\hline accent & $\square$ & $\square$ & $\square$ & $\square$ & $\square$ & $\square$ & $\square$ & accent \\
\hline
\end{tabular}

